\title{
Precipitation data considerations for evaluating subdaily changes in rainless periods due to climate change
}

\section{J.V. Bonta}

\begin{abstract}
Quantifying magnitudes and frequencies of rainless times between storms (TBS), or storm occurrence, is required for generating continuous sequences of precipitation for modeling inputs to small watershed models for conservation studies. Two parameters characterize TBS, minimum TBS (MTBS) and average TBS (ATBS) - both vary monthly and are calculated by assuming TBS follows an exponential distribution. Detecting changes in these parameters due to climate is important for precipitation and climate studies at short time and small spatial scales, but there are issues with depth resolution of precipitation data that must first be investigated. Precipitation data having one-minute temporal and $0.25 \mathrm{~mm}(0.01$ in) depth resolutions from the UDSA Agricultural Research Service North Appalachian Experimental Watershed (NAEW) at Coshocton, Ohio, were used to determine the spatial variability and consistency of estimates over the $425 \mathrm{ha}(1,050 \mathrm{ac})$ facility and the impacts of coarsening the depth resolution of data 10 times to $2.54 \mathrm{~mm}(0.1 \mathrm{in})$. The magnitudes and trends of changes in MTBS and ATBS are determined for three rain gauges over the NAEW and extended to other gauges in the Ohio region. Approximately 5,800 parameter pairs were computed for different data configurations. Small spatial scale, NAEW high-resolution precipitation data shows consistent MTBS and ATBS long-term values for each month but more variability in estimates for MTBS than ATBS. Climate change trends for MTBS and ATBS are not apparent and generally consistent for different NAEW gauges, except for November when all gauges were consistently significant for ATBS. There is a weak indication that the fall months may be affected by significant shortening of ATBS at the NAEW and in northeastern Ohio due to climate change, but more data are needed. An imposed, coarser NAEW data resolution results in consistent no-trend indications for MTBS, but not for ATBS. The coarse-resolution data may not be adequate to characterize TBS for investigating changes due to climate change unless more data preparation is performed, such as identifying and excluding dry times when precipitation may have occurred. Precipitation records with mixed resolution data cannot be used to detect climate changes of dry periods. More data and data preparation are needed to arrive at firm conclusions regarding climate change effects on TBS in Ohio.
\end{abstract}

Key words: climate change—drought—precipitation—-times between storms

\begin{abstract}
Variabilities of stream water and its quality are driven and limited by spatial and temporal weather elements in a particular climate over watersheds (e.g., air temperature, precipitation distribution and intensities, etc.). Weather and climate (large area drivers) are also major factors that determine the anthropogenic activities (local area factors at the small watershed/field scale) appropriate for a watershed landscape and thus further affect stream water quan-
\end{abstract}

to large watersheds that aggregate the effects of smaller watersheds. However, for modeling ungauged watersheds, often long precipitation records are not available, or their spatial distribution is deficient. Consequently, many times these precipitation inputs are stochastically synthesized so that statistical characteristics are maintained in the area of interest. These stochastically generated inputs must statistically reflect anticipated changes due to a changing climate, and investigations are necessary into how statistical parameters are changing in observed data. However, data characteristics vary and must first be investigated. This study examines precipitation data characteristics that may affect conclusions regarding observed changes in dry times between storms (TBS) due to changing climate and corresponding changes in parameters that must be determined for modeling.

Approaches to evaluating the effects of climate change on the environment can range from simple percentage changes of model inputs to the outputs of complex global circulation models (GCM; Pope et al. 2000). Currently, GCM outputs (monthly and daily mean temperature and precipitation) are available over the continental United States at a resolution of one-eighth degree latitude and longitude (approximately 10 to $12 \mathrm{~km}$ [6.2 to 7.5 mi]) (PCMDI 2011). Thus, GCMs do not supply adequate spatial and temporal outputs for storms often needed for small watershed/ field modeling. A better understanding of the effects of climate change on storms over smaller watersheds is needed.

Many important studies have documented extreme values of weather elements over large areas. Groisman et al. (2005) found that extreme daily precipitation during the period from 1970 to 2002 in the central United States was statistically significantly increasing at rate of $26 \%$ per 30 years. Groisman et al. (2001) documented increasing large watershed streamflows due to increasing extreme rainfall over the United States. Groisman et al. (2008) showed that return periods decreased over the last 40 years for periods with no rain above a threshold precipitation during the warm season in the eastern United States. The increase in associated dry durations was

James V. Bonta is a research hydraulic engineer at the USDA Agricultural Research Service National Sedimentation Laboratory in Oxford, Mississippi. 
lengthening at a rate of $1 \%$ per 40 years. These studies document broad changes in extremes occurring over large areas. However, modeling the effects of land management changes requires subdaily precipitation over small watershed- and farm-field-size areas for an entire year.

In a review of the literature, Nearing et al. (2004) concluded from a modeling study that runoff and erosion will increase $2 \%$ and $1.7 \%$, respectively, per $1 \%$ increase in precipitation (Pruski and Nearing 2002). Projected increases or decreases in precipitation and temperature can worsen agricultural sustainability in important major agricultural-producing areas. Consequently, an understanding of changes in processes in the hydrological cycle will be important. In particular, understanding changes in hydrological processes occurring between rainfall events will be important to provide mitigation guidance for the agricultural community. Delgado et al. (2011) outline specific conservation practices that can be implemented to mitigate and adapt to the effects of climate change based on current knowledge.

Data Characteristics. The primary source of historical subdaily data useful for investigating changes in precipitation characteristics due to climate change in the United States is data collected by the National Weather Service (NWS). These data have time and depth resolution characteristics that may limit their suitability for analyzing dry TBS as explained in the Materials and Methods section. However, because of the national extent of the data, evaluating their suitability becomes important.

Another source of data is from smaller-scale, experimental watershed locations operated by the USDA Agricultural Research Service (ARS). At these locations, there is often a high-density network of precipitation gauges with good temporal and depth resolution data (high resolution). The two data sets with differing characteristics are complementary in exploratory studies.

Measurements of many hydrological cycle components have been uniquely measured at the ARS North Appalachian Experimental Watershed (NAEW) near Coshocton, Ohio, since its establishment in 1935, such as evapotranspiration and groundwater recharge from lysimeters, small ( 0.6 ha $\left.\left[\begin{array}{ll}1.5 & \mathrm{ac}\end{array}\right]\right)$ watershed runoff, soil moisture, weather elements, etc. These data can be used to examine changes in hydrological cycle components during dry and wet periods. The NAEW is an outdoor laboratory for land and water management research, is equipped with unique hydrological instruments, and has an associated long-term database. These measurements are often considered local and not regional or continental. However, many data have been collected concurrently for varying durations and can provide insight into how the hydrological cycle responds under a changing climate. The unique data set includes measurements made at a subdaily temporal resolution over small areas. Preliminary investigations of the stationarity of air temperature data in particular at the NAEW revealed that air temperature data have been increasing since about 1979 (Bonta and Barker 2010). This is approximately the same year of global climate change found in the Intergovernmental Panel on Climate Change report (Trenberth et al. 2007).

Precipitation Element Modeling. Bonta (2004) developed a stochastic storm mode for generating continuous sequences of precipitation around four elements of storm precipitation: TBS, storm durations, storm depths, and within-storm intensities for use in small watersheds. Times between storms is the fundamental component for storm precipitation studies because it defines storms that subsequently can be investigated for changes in storm intensities and other precipitation characteristics. By using storms, the daily data constraint often used in modeling is removed. Consequently, storms can span midnight, and more than one storm can occur in day. If TBS is changing, then storm durations will be changing. Similarly, if storm depth and duration are changing concurrently, then storm intensities will be changing. Equation forms that could be used to parameterize the modeling of TBS parameters have been identified for unmonitored areas (Bonta and Nayak 2008; Bonta 2001, 2003). However, if climate change affects TBS, then identifying and quantifying TBS effects is important for representative modeling.

There are two useful parameters that characterize TBS in modeling: minimum time between storms (MTBS), which groups bursts of precipitation into independent storms, and average time between storms (ATBS). The latter can be used to represent the frequency distribution of dry periods separating independent storms. Often the MTBS is set at a fixed value (e.g., six hours by Huff [1967]); however, several studies by the author have shown that these parameters vary monthly (Bonta and Nayak 2008; Bonta 2001, 2003). This paper focuses on these two objectively and empirically determined parameters. An iterative method that determines when an exponential distribution fits the TBS data is the underlying principle for calculating TBS parameters, as explained later. Another approach to determining the distribution of dry times was presented by Santhanam and Kantz (2008). However, they investigated the distribution of dry periods between extreme events and not continuous events as examined in the present paper.

Bonta (2001) used NWS data in the Colorado plains region east of the Rocky Mountains to investigate spatial variability of long-term estimates of TBS parameters; climate change was not an objective. The procedure used to develop the data set was time consuming and required independent data sets of adjacent recording and nonrecording rain gauges. The result was that many TBS values were discarded because they failed to represent the TBS values (rainless periods in the recording gauge record when storage gauges show precipitation). Because of the extensive rain gauge network operated by the NWS nationwide, the present paper is a pilot study evaluation to investigate the adequacy of the data to detect changes in TBS due to possible climate change, without extra data preparation. IfTBS parameters could be determined without extra preparation, a denser gauge network and, thus, longer data sets would be available, and analyses much simpler.

Objectives and Approach. The overall objective is to explore precipitation data characteristics relevant to determining the effects of climate change on two TBS parameters at the subdaily time and small spatial scales (MTBS and ATBS). Specific objectives are to determine the variability in dry TBS using high- and coarse-resolution data in a small area, to determine the two parameters more regionally in Ohio, and to explore the effects of precipitation data characteristics on potential climate change trends in Ohio of the two parameters over the past $60+$ years and over the most recent $\sim 30$ years.

The approach is exploratory and statistical using an exponential-frequency distribution. Two parameters characterizing TBS (ATBS and MTBS) are computed for rain gauges 
Table 1

Precipitation stations used (locations in figure 1) and data characteristics.

\begin{tabular}{|c|c|c|c|c|c|c|c|}
\hline $\begin{array}{l}\text { Rain } \\
\text { gauge } \\
\text { ID* } \\
\end{array}$ & $\begin{array}{l}\text { Precipitation } \\
\text { station name }\end{array}$ & State & $\begin{array}{l}\text { Start } \\
\text { year of } \\
\text { recordt }\end{array}$ & $\begin{array}{l}\text { Percentage } \\
\text { of record } \\
\text { with } \\
\text { hundredths } \\
\text { resolution } \\
\end{array}$ & $\begin{array}{l}\text { Percentage } \\
\text { of record } \\
\text { with } \\
\text { tenths } \\
\text { resolution } \\
\end{array}$ & $\begin{array}{l}\text { Average } \\
\text { Year of } \\
\text { resolution } \\
\text { change }\end{array}$ & $\begin{array}{l}\text { annual } \\
\text { precipitation } \\
(\mathrm{mm}) \S\end{array}$ \\
\hline 331197 & Cambridge & Ohio & 1948 & 50 & 50 & 1973 & 995 \\
\hline 331657 & Cleveland WSO AP & Ohio & 1949 & 100 & 0 & nał & 983 \\
\hline 331786 & Columbus WSO AP & Ohio & 1949 & 100 & 0 & na & 978 \\
\hline 151855 & Covington WSO & Kentucky & 1951 & 100 & 0 & na & 1,082 \\
\hline 332791 & Findlay WPCC & Ohio & 1948 & 27 & 73 & 1964 & 938 \\
\hline 333375 & Greenville WTP & Ohio & 1949 & 100 & 0 & na & 947 \\
\hline 338378 & Jenkins Dam Burr Oak & Ohio & 1953 & 68 & 32 & na & $\|$ \\
\hline 334865 & Mansfield WSO AP & Ohio & 1949 & 100 & 0 & na & 1,098 \\
\hline 336375 & Oxford & Ohio & 1948 & 100 & 0 & na & $\|$ \\
\hline 366993 & Pittsburgh ASOS & Pennsylvania & 1925 & 100 & 0 & na & 961 \\
\hline 336781 & Portsmouth-Sciotoville & Ohio & 1954 & 47 & 53 & 1975 & 1,053 \\
\hline 468286 & Smithville & West Virginia & 1950 & 54 & 46 & 1979 & $\|$ \\
\hline 338357 & Toledo Express WSO AP & Ohio & 1960 & 100 & 0 & na & 844 \\
\hline 339406 & Youngstown WSO AP & Ohio & 1949 & 100 & 0 & na & 966 \\
\hline 339422 & Zanesville WWTP & Ohio & 1948 & 52 & 48 & 1973 & $\|$ \\
\hline 103 & NAEW-103 & Ohio & 1938 & 100 & 0 & na & 923 \\
\hline 109 & NAEW-109 & Ohio & 1940 & 100 & 0 & na & 984 \\
\hline 115 & NAEW-115 & Ohio & 1939 & 100 & 0 & na & 961 \\
\hline
\end{tabular}

* Rain-gauge identification for National Weather Service (NWS) gauges is the NWS coop ID and for North Appalachian Experimental Watershed (NAEW) gauges is the NAEW gauge number.

† Month of starting of record varies, and ending months for records are September of 2010 for NWS gauges and December of 2010 for NAEW gauges.

$\ddagger$ na $=$ not applicable.

$\S$ Normal date range is 1971 to 2000. NWS values taken from state summaries (Rogers 2011).

|| Annual summary not available.

on the NAEW and in the Ohio region. The NAEW gauges provide insight into expected stability and temporal variability of parameter estimates on a small spatial and temporal scale. The more regional gauges provide a broader appraisal of these factors. The data are evaluated to determine the potential temporal changes in the parameters due to climate change. The long-term utility of the results will be for modeling climate change in a storm model, to aid in evaluating more detailed hydrological data at the NAEW under changing climate, to combine a storm generator with a weather generator, and to explore linking small scale storm modeling to GCM outputs that must be spatially and temporally disaggregated. In particular, results from the present study will guide further research using unique NAEW data sets, such as air and soil temperatures, evapotranspiration, groundwater recharge, etc., during dry periods.

\section{Materials and Methods}

Precipitation Data Sources. Precipitation data came from two sources, the NAEW and the NWS. National Weather Service data records had to have hourly data with records at least 50 years in length ending in 2010. Fifteen gauges were selected for visual spatial representativeness mostly in Ohio (table 1 and figure 1). Most NWS data records began approximately in 1949, resulting in record lengths of approximately 62 years. NAEW records began approximately in 1939 for record lengths of approximately 71 years. Normal NWS precipitation (years 1971 to 2000) for individual gauges in Ohio ranges from $844 \mathrm{~mm}$ (33.21 in) to $1,098 \mathrm{~mm}$ (43.24 in) (Rogers 2011). Average normal precipitation amounts are $956 \mathrm{~mm}$ (37.63 in) and 986 $\mathrm{mm}$ (38.82 in) for NAEW and NWS gauges, respectively. Average annual precipitation for the Ohio gauges is $979 \mathrm{~mm}$ (38.56 in). The monthly distribution of precipitation at the NAEW is shown in figure 2 and has a similar pattern in the Ohio region. Historical winter precipitation measurements from nearly any data source have the largest error, as much as $27 \%$ less on average (McGuinness 1966).

North Appalachian Experimental Watershed Data. The NAEW is a 425 ha $(1,050 \mathrm{ac})$ experimental watershed facility operated by the USDA ARS (Owens et al. 2010; Harmel et al. 2007) and is located in east-central Ohio (enlarged map in figure 1). Many small, gauged experimental watersheds on which land management changes are evaluated comprise the monitoring infrastructure. Associated with the small watersheds are recording rain gauges that monitor local watershed precipitation at high resolution (time and depth resolutions of 1 minute and $0.25 \mathrm{~mm}$ [0.01 in], respectively). The network of precipitation data began soon after establishment of the NAEW in 1935. Data were tabulated in breakpoint form for most of each year from weighing-bucket gauges - a point is tabulated whenever rain intensity changes. Breakpoint data are high-resolution data that trace the actual intensity changes in a storm, compared with equal-time interval 


\section{Figure 1}

Locations of North Appalachian Experimental Watershed (NAEW) and National Weather Service (NWS) rain gauges.

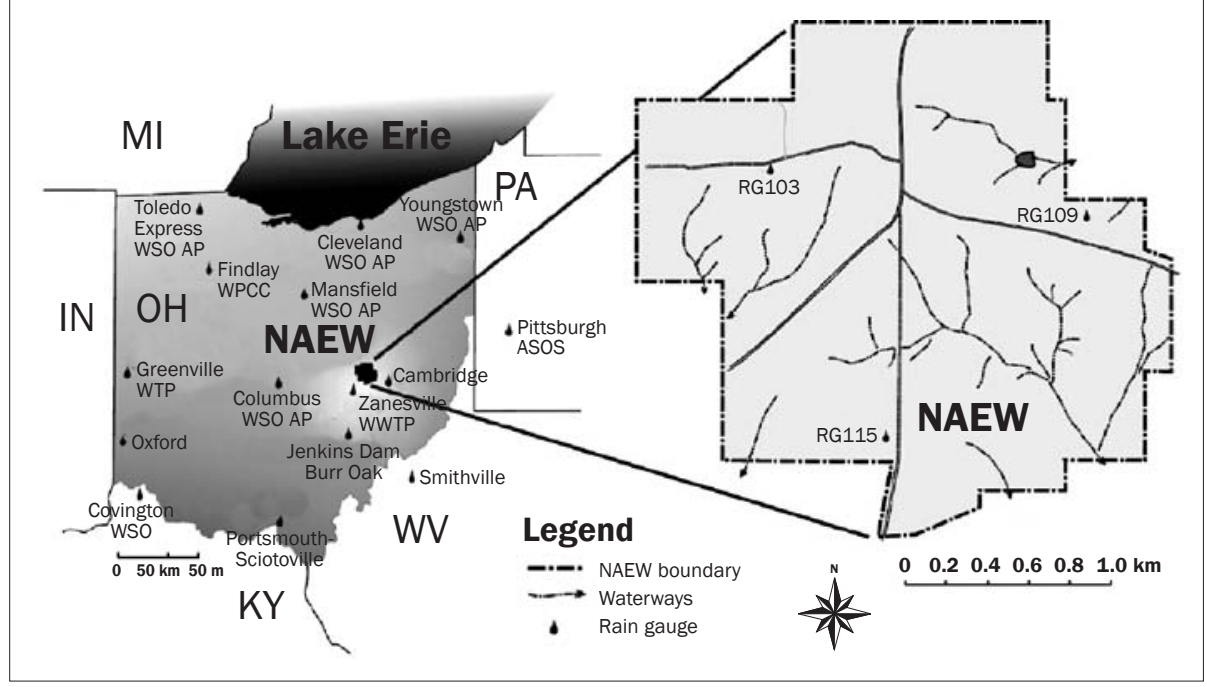

data (e.g., 60 minutes) or data collected with a coarser depth resolution.

Three NAEW gauges were selected (NAEW-103, NAEW-109, and NAEW115). These were chosen because they are located at the periphery of the NAEW and are about $1.5 \mathrm{~km}(0.9 \mathrm{mi})$ apart from each other (enlarged map in figure 1). These gauges are useful to quantify expected variability of MTBS and ATBS over a small area

\section{Figure 2}

Distribution of average monthly precipitation at the North Appalachian Experimental Watershed.

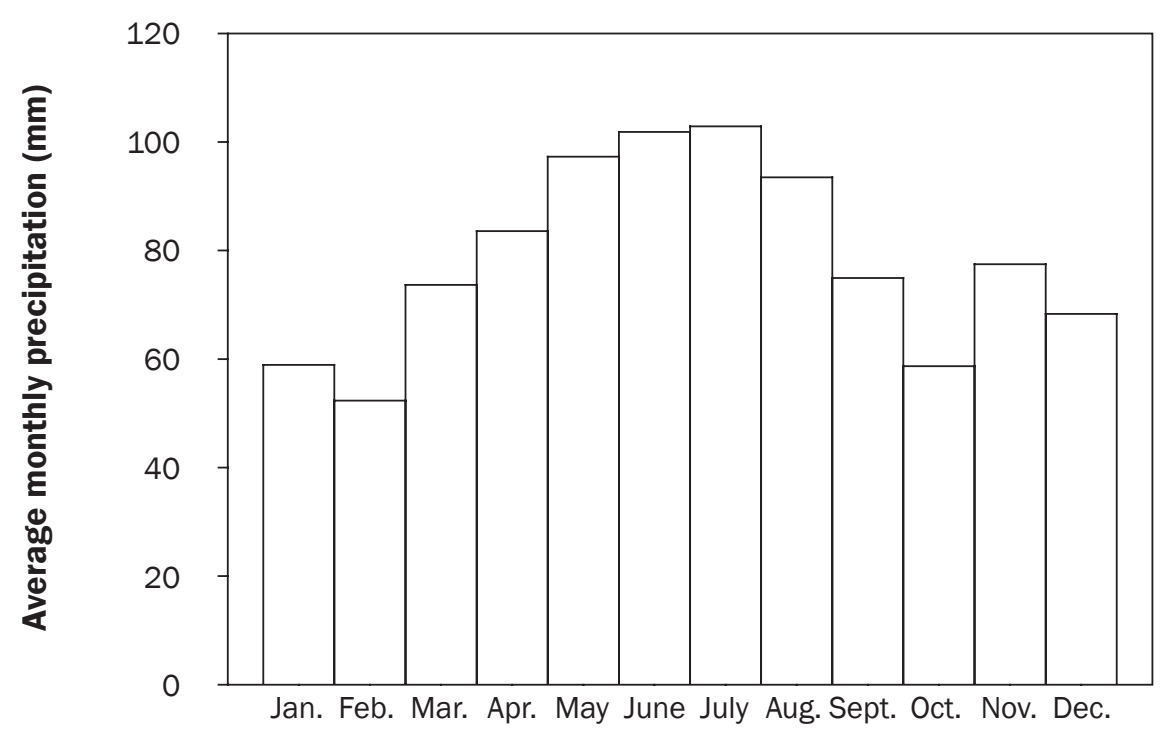

Month work of recording precipitation gauges. Fifteen precipitation gauges with long hourly records were selected in Ohio (National Weather Service 2011) and surrounding states to determine whether NAEW data findings are more regional (figure 1). Instrumentation changes during the 1970 s changed the depth resolution of some data by a factor of 10 from $0.25 \mathrm{~mm}$ (0.01 in) to $2.54 \mathrm{~mm}$ (0.1 in). The consequence of this resolution change is that TBS may be longer because the beginning and ending times of storms are not as accurately detected. The percentage of the length of NWS records with a $2.54 \mathrm{~mm}$ resolution are given in table 1 , along with the year the resolution change began. Nine gauges had no resolution change. The records of the remaining six are termed "mixed-resolution" gauges.

Exponential Method for Identifying Storms. A minimum dry period (no precipitation) is often used to separate groups of precipitation bursts into storms. In a precipitation record, bursts of precipitation are separated by periods of no precipitation (figure $3 ; \mathrm{D}_{\mathrm{i}}$ ). Intuitively, dry periods of the order of minutes between bursts of precipitation $\left(\mathrm{B}_{\mathrm{i}}\right)$ would belong in the same storm as the bursts. However, bursts of precipitation separated by dry-period durations of the order of days would not belong in the same storm. Consequently, there is a MTBS that separates bursts of precipitation. For example, figure 3 shows that continuous precipitation bursts $\mathrm{B}_{1}$ and $\mathrm{B}_{2}$ are separated by dry-period duration $\mathrm{D}_{1}$ (bursts include solid and clear boxes); bursts $\mathrm{B}_{2}$ and $\mathrm{B}_{3}$ are separated by $\mathrm{D}_{2}$; and $\mathrm{B}_{3}$ and $\mathrm{B}_{4}$ are separated by $\mathrm{D}_{3}$. A dry period greater than MTBS (e.g., $\mathrm{D}_{2}$ ) separates groups of bursts of precipitation and short dry periods from one another, and thus $\mathrm{D}_{i}$ $\geq$ MTBS identifies storms. Dry periods less than MTBS are included in storms. In figure $3, \mathrm{D}_{3}<\mathrm{D}_{1}<\mathrm{MTBS}<\mathrm{D}_{2}$, and two storms are apparent. Often a constant, arbitrary MTBS value is used to separate storms (e.g., six hours by Huff [1967]). However, Bonta (2001) showed that MTBS varies monthly.

Restrepo and Eagleson (1982) developed the exponential method of computing the MTBS to identify storms in a precipitation record used in the present paper. Their iterative method assumes that the MTBS is found when $\mathrm{D}_{\mathrm{i}}$ greater than MTBS form an exponential distribution:

$\mathrm{F}\left(\mathrm{TBS}_{i}\right)=e^{(-\mathrm{TBS} i \div \mathrm{ATBS})}\left(\mathrm{TBS}_{i} \geq \mathrm{MTBS}\right)$, 


\section{Figure 3}

Definition sketch for storm depth and duration, storm intensities, minimum time between storms (MTBS), and effect on MTBS due to change in depth resolution of data. $B_{i}=$ rainfall burst. $D_{i}=$ dry-period duration. Coarser parameter labels have the character " $\mathrm{t}$ " in them, and clear boxes represent precipitation depths subject to change due to the coarser depth resolution.

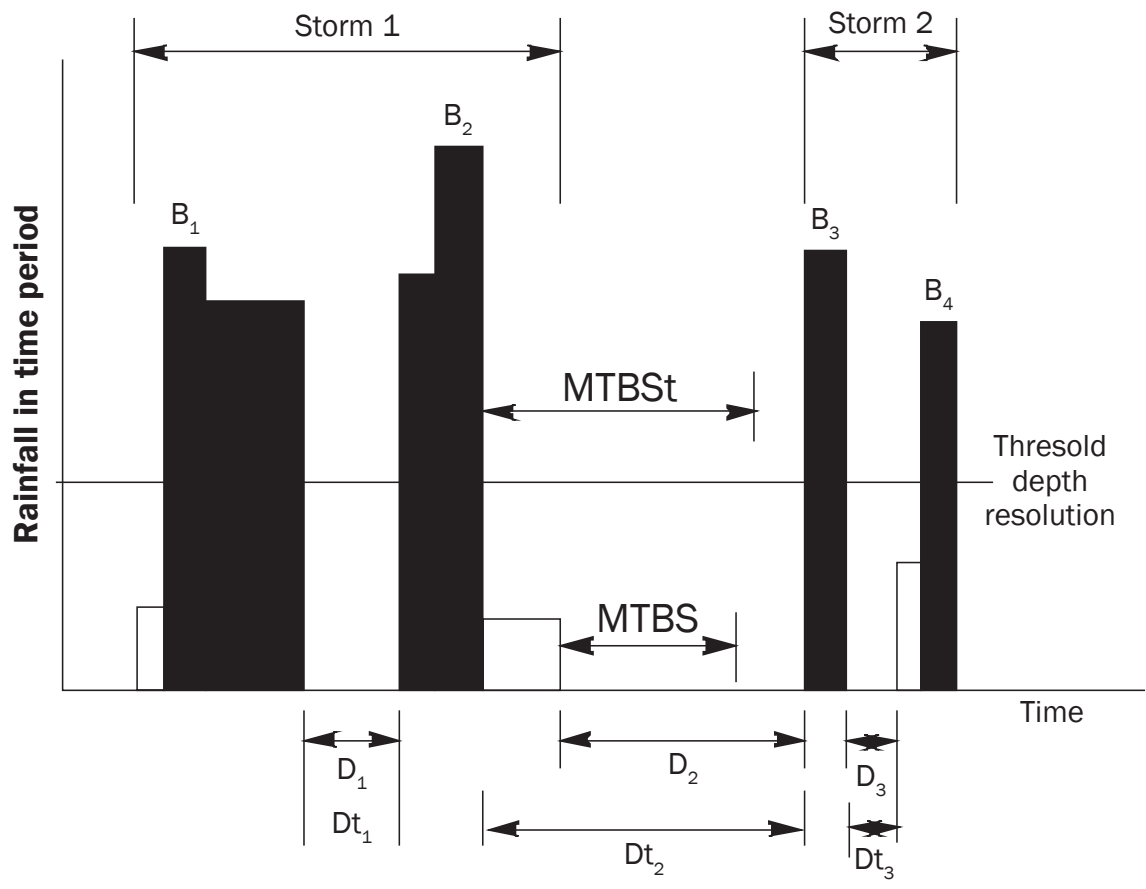

where $\mathrm{F}\left(\mathrm{TBS}_{i}\right)$ is cumulative distribution function (fraction greater than); $\mathrm{TBS}_{i}$ is individual value of TBS, time units; and ATBS is average time between storms, time units.

The exponential frequency distribution has the property that the mean and standard deviation are equal (coefficient of variation $[\mathrm{CV}]$ is unity) and, consequently, is a one-parameter model (the mean, ATBS). The iterative process begins with computing $\mathrm{CV}$ for all dry periods for a given month. If $\mathrm{CV}$ is greater than unity, then the shortest durations are eliminated from the data set, and $\mathrm{CV}$ is recomputed with the remaining data. The process is repeated until $\mathrm{CV} \leq 1$. The interpolated TBS duration at $\mathrm{CV}=$ 1 becomes the MTBS. Seasonal variation throughout a year is characterized by developing monthly parameters. The exponential method is ideal for use with subdaily data (as opposed to daily precipitation data) because TBS parameters shorter than a day can be determined. Monthly TBS are associated with the beginning month of the dry period and can extend into one or more succeeding months. It is apparent that knowledge of how the two parameters change is important for stochastic modeling in general and for modeling storms during a changing climate.

The significance of the exponential distribution of TBS is that interarrival times of events in a Poisson process follow this distribution, making the events (storms) approximately statistically independent. This assumption eliminates the need to determine serial correlation of events, simplifying storm modeling. Examples of the fit of the exponential method to TBS data are shown in figure 4 for NAEW-115 (figure 1) used in the present study. The mostly linear trend of points on a semilog grid suggests the exponential distribution fits the data. The exponential method is used to characterize storms in the present paper and in the storm model (Bonta 2004).

Applying the exponential method yields the two parameters for a month. The method was used to compute approximately 5,800 pairs of MTBS and ATBS values using the data configurations described next.

Adjustments to the Depth Resolution of Data Using the Exponential Method. Changes in NWS precipitation measurement technology resulted in a coarser depth resolution of data from 0.25 to $2.54 \mathrm{~mm}$
(0.01 to $0.1 \mathrm{in}$ ) in the $1960 \mathrm{~s}$ and $1970 \mathrm{~s}$. Figure 3 shows the effect a change in depth resolution (rounding to $2.54 \mathrm{~mm}$ ) can have on MTBS (and thus ATBS) results. (Coarser parameter labels have the character " $\mathrm{t}$ " in them, and clear boxes represent precipitation depths subject to change to the coarser depth resolution.) The high-resolution data would be as shown including the clear boxes. For example, dry duration does not change for $\mathrm{Dt}_{1}\left(\mathrm{Dt}_{1}=\mathrm{D}_{1}\right)$ because the bursts are greater than the resolution of the data. However, $\mathrm{Dt}_{2}>\mathrm{D}_{2}$ because the clear boxes would round to zero. $\mathrm{Dt}_{3}=\mathrm{D}_{3}$ because the clear box would round to the coarser depth resolution. Consequently, $\mathrm{Dt}_{\mathrm{i}}$ would tend to be longer than $\mathrm{D}_{i}$, resulting in longer ATBS and MTBS. The possible interpretation of results would be to attribute longer TBS to climate change instead of measurement technology. This is illustrated in figure 5 by using mixed resolution data from Cambridge, Ohio (table 1 ), in which five-year periods of ATBS are plotted; the results are the same after the year of instrument change (1973) no longer influences the values. Mixed resolution results are given less weight in the present paper than the records with 100\% high-resolution data.

Statistical Analysis of Times-BetweenStorms Parameters. National Weather Service and NAEW data were scanned for periods of record during which the gauge was not in operation or not operating properly. These dry periods were coded for elimination because they are erroneous. One problem identified in NWS data was the possibility for a large dry time that was apparently not real. These uncoded periods were identified and coded for elimination prior to analyzing the data with the exponential method. Data periods during which NWS data were coded due to various reasons were omitted from the data set.

Preliminary analysis of data trends suggested that ATBS and MTBS could be computed most of the time if TBS data were grouped into five-year periods. Furthermore, because the two parameters vary with month, ATBS and MTBS were computed for each month in each five-year period. For example, all May data in a five-year period were collapsed to determine May MTBS and ATBS. The exception to the five-year period was the last period that ended in 2010, which had to have at least three years of data if the period of record was not evenly divisible by five. The beginning year for five-year groups was the 


\section{Figure 4}

Example of exponential distribution trends of times between storms (TBS) for every other month starting with January for North Appalachian Experimental Watershed rain gauge 115 (lines connect points).

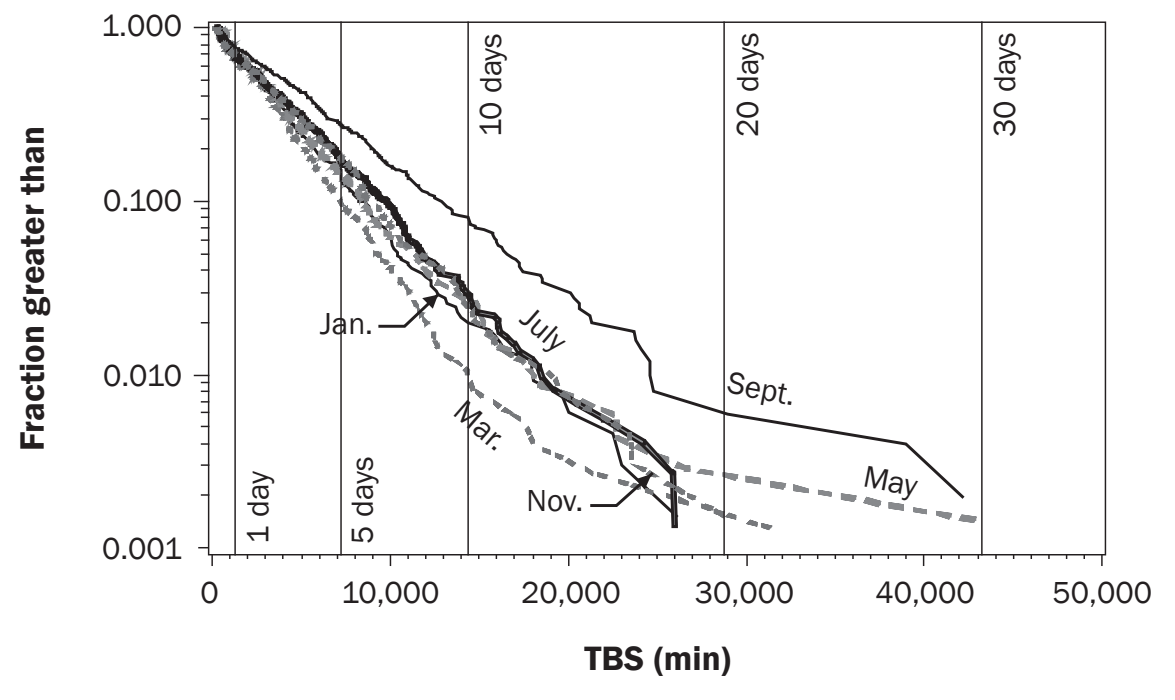

beginning year of record (table 1). The trends in the two parameters for each month for the five-year periods were visualized by graphing parameters against the midpoint of the year range and rank correlation computed for each month. A five-year trend is termed the "temporal variability" of the parameter and is

\section{Figure 5}

Example of effect of change in depth resolution on average time between storms (ATBS) for Cambridge, Ohio, National Weather Service precipitation gauge for May.

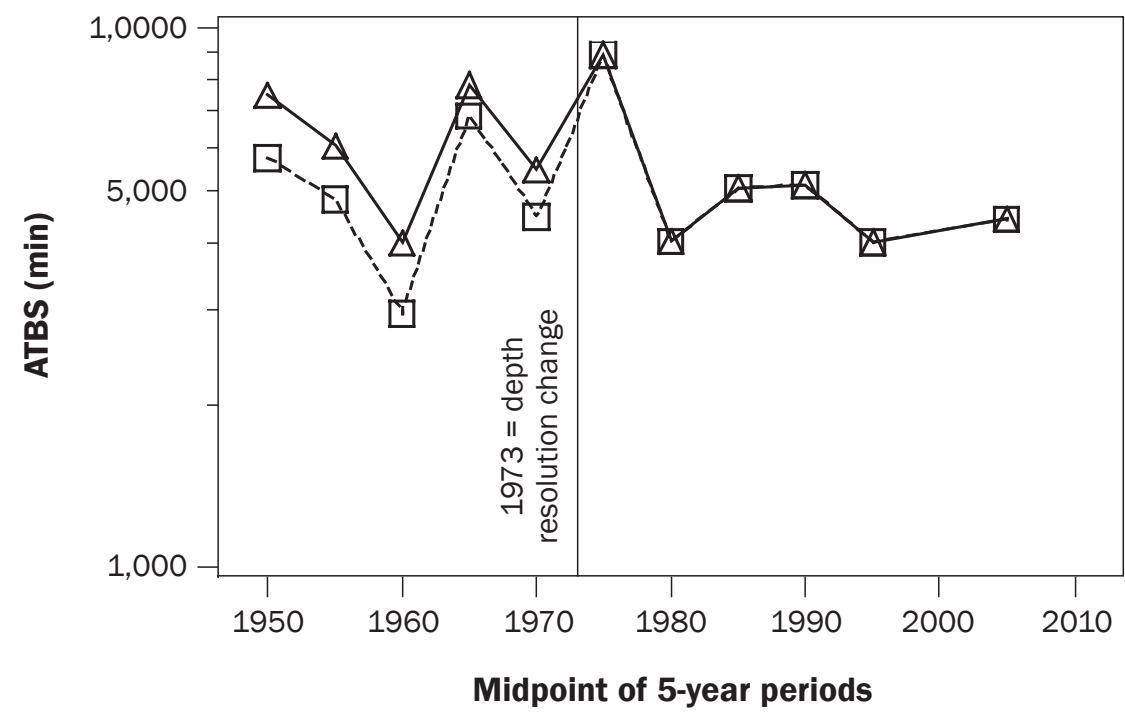

Legend

$\triangle$ Depth resolution $=2.54 \mathrm{~mm} \quad \because$ Depth resolution $=0.25 \mathrm{~mm}$
Superimposed graphs were made of calculated $p$-values versus month for each gauge.

Additionally, all data were collapsed across years for each month, and an overall value computed (representing an average value for the gauge for each month). This is termed the "long-term" value. Examples of five-year variations are graphed for each parameter as the ratio of the five-year period to the longterm value. The variability of the five-year values about unity is a visual measure of its representativeness; with no variability, the long-term value would be the same (representative) as the five-year averages, and all points would fall on the unity line.

Data from NAEW gauges were subjected to an artificial $2.54 \mathrm{~mm}$ (0.1 in) depth (coarse) resolution change. The high- and coarse-resolution results are compared to show its effect and to aid in interpreting the coarser NWS data. The NAEW high-resolution data are also compared with a fixed 360-minute (6-hour) MTBS often used in precipitation analyses to show the nonrepresentativeness of the fixed value. NWS data were also subjected to the coarser resolution where the entire period had higher resolution data, and the data were also made coarser in earlier records that had mixed high- and coarse-resolution data (figure 5).

Changes in Time Trends since 1979. The Intergovernmental Panel on Climate Change report (Trenberth 2007) suggested that there has been a trend in various weather variables since approximately 1979 due to climate change, and preliminary analysis of NAEW air temperature data suggests the same. Some data in the present paper were also subjected to rank correlation analyses during this period to detect a changing climate since 1979 (last $\sim 30$ years). There are at most only six 5-year periods from which rank correlation could be computed since 1979 .

\section{Results and Discussion}

Effects of Depth-Resolution Changes and Monthly Variation of Long-Term TimesBetween-Storms Parameters over the North Appalachian Experimental Watershed. MTBS varies greatly from month to month for NAEW breakpoint data when data are collapsed across all years (figure 6 and upper part of table 2). MTBS varies from $201 \mathrm{~min}$ utes in February to 577 minutes in June and shows two peaks in the year. However, there is little variation between gauges. Coefficients of variation range from $1 \%$ to 
$11 \%$ with least variation occurring from January through June.

These values are notably different from a 6-hour (360-minute) MTBS often used in precipitation analyses (ratios of exponential to 360-minute values range from 0.6 to 1.6). April, May, and June show the greatest departures from the 6-hour period (middle table 2).

When a depth resolution of $2.54 \mathrm{~mm}$ (0.1 in) is imposed on NAEW data, both the magnitude and variability of MTBS estimates increase greatly (lower part of table 2). Average MTBS ranges from $342 \mathrm{~min}-$ utes in July to 2,714 minutes in November. Coefficients of variation increase and range from $3 \%$ to $89 \%$, with least variation occurring in April through July. Ratios of coarser to higher resolution average MTBS show that MTBSs are always longer, ranging from 1.1 to 9.3 times.

Average time between storms also varies greatly from month to month throughout the year for NAEW $0.25 \mathrm{~mm}$ (0.01 in) resolution breakpoint data (figure 7 and upper part of table 3) when data are collapsed

\section{Figure 6}

Long-term minimum time between storms (MTBS) versus month for North Appalachian Experimental Watershed rain gauges (NAEW) collapsed across years (resolution $=0.25 \mathrm{~mm}$ ).

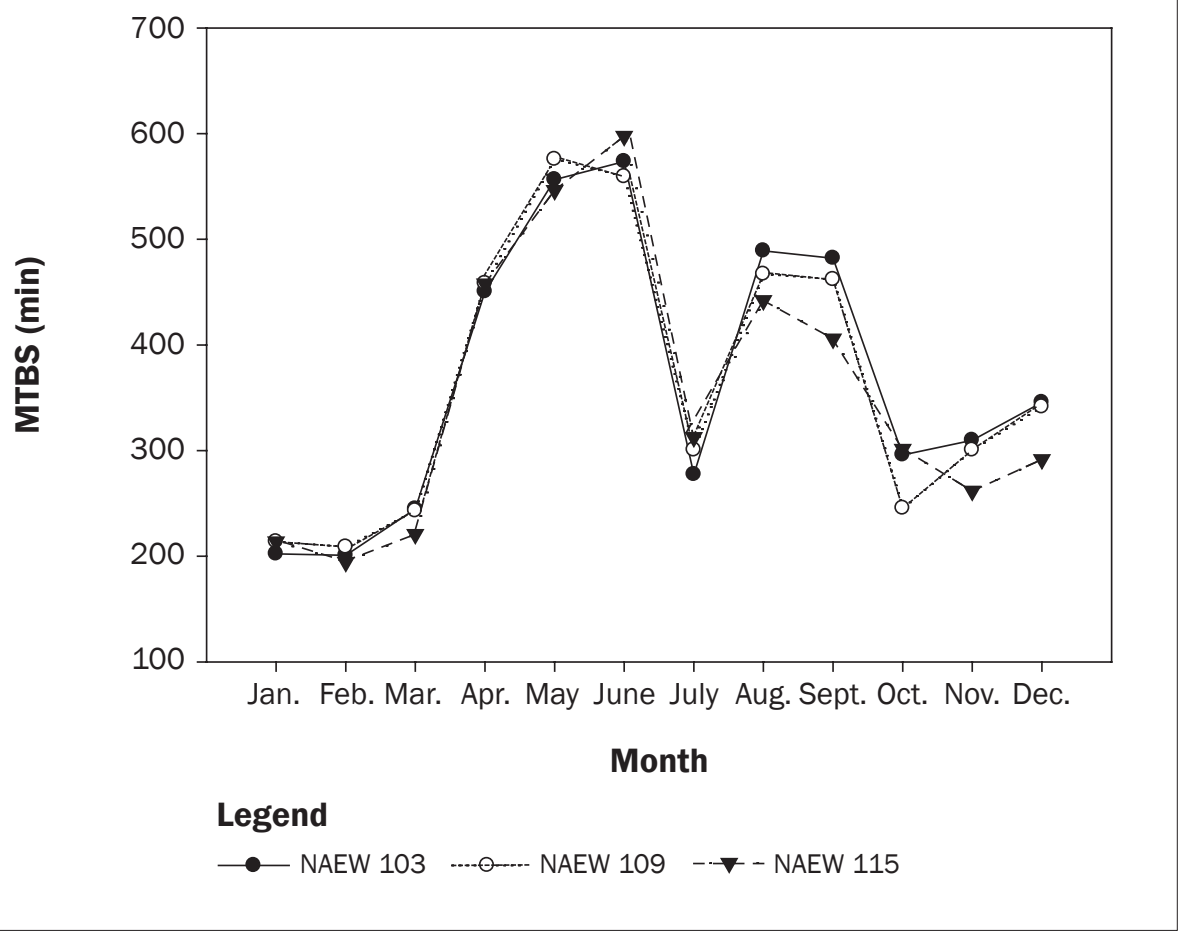

Table 2

Long-term minimum time between storms (MTBS) for North Appalachian Experimental Watershed (NAEW) rain gauges for both resolutions (data collapsed across all years for each month).

\begin{tabular}{|c|c|c|c|c|c|c|c|c|c|c|c|c|c|}
\hline $\begin{array}{l}\text { Rain } \\
\text { gauge } \\
\text { ID }\end{array}$ & $\begin{array}{l}\text { Depth } \\
\text { resolution } \\
(\mathrm{mm})\end{array}$ & Jan. & Feb. & Mar. & Apr. & May & June & July & Aug. & Sept. & Oct. & Nov. & Dec. \\
\hline 103 & 0.25 & 202 & 201 & 245 & 450 & 556 & 574 & 277 & 489 & 482 & 296 & 310 & 346 \\
\hline \multirow[t]{3}{*}{115} & 0.25 & 214 & 194 & 221 & 458 & 546 & 598 & 313 & 442 & 406 & 301 & 262 & 292 \\
\hline & $n *$ & 662 & 623 & 765 & 709 & 680 & 619 & 739 & 539 & 489 & 544 & 640 & 615 \\
\hline & Average & 210 & 201 & 236 & 456 & 559 & 577 & 297 & 466 & 450 & 281 & 291 & 326 \\
\hline 103 & 2.54 & 1,041 & 1,249 & 952 & 1,038 & 698 & 670 & 364 & 922 & 1467 & 605 & 5,219 & 484 \\
\hline 109 & 2.54 & 575 & 285 & 387 & 822 & 511 & 686 & 302 & 539 & 718 & 688 & 378 & 668 \\
\hline \multirow[t]{2}{*}{115} & 2.54 & 1,443 & 954 & 877 & 1,041 & 625 & 716 & 361 & 521 & 711 & 870 & 2,545 & 1,058 \\
\hline & $\begin{array}{l}\text { Ratio of } n \\
\quad \text { (resolution } \\
2.54 / 0.25 \text { ) }\end{array}$ & 0.5 & 0.5 & 0.5 & 0.6 & 0.7 & 0.8 & 0.8 & 0.7 & 0.7 & 0.6 & 0.5 & 0.5 \\
\hline
\end{tabular}

$\star_{n}=$ average number of time between storms (TBS) values found when CV $=1$ (TBS $>$ ATBS).

$\dagger \mathrm{CV}=$ coefficient of variation (\%). 
across years for each month. ATBS varies from 3,183 minutes (2.2 days) in March to 5,690 minutes (4 days) in August and shows a dominant peak in the fall. The average of all monthly values is 4,255 $\mathrm{min}$ (3 days). However, as with corresponding MTBS, there is little variation between gauges. Coefficients of variation range from $1 \%$ to $3 \%$ with least variation occurring from March through June (table 3).

When a depth resolution of $2.54 \mathrm{~mm}(0.1$ in) is imposed on NAEW data, both the magnitude and variability of ATBS estimates increase greatly (lower part of table 3). The average NAEW ATBS ranges from 5,542 minutes (3.8 days) in July to 10,248 minutes (7.1 days) in November. Coefficients of variation are greater and range from 3\% to $30 \%$, with least variation occurring in April through July, the same as for MTBS. Ratios of average MTBS show the coarser resolution results to be always longer than the high-resolution data, ranging from 1.4 to 2.6 times.

The average numbers of TBS values $(n)$ found greater than MTBS for each month when data were collapsed across years varied little among the three NAEW gauges (upper table 2). An $n$ value applies to paired MTBS and ATBS. Average numbers ranged from 489 to 765 values, with an overall average of 635 values. When data are subjected to a coarser resolution, the average number of values ranged from 290 to 560 values (lower

Figure 7

Long-term average time between storms (ATBS) versus month for North Appalachian Experimental Watershed rain gauges (NAEW) collapsed across years (resolution $=0.25 \mathrm{~mm}$ ).

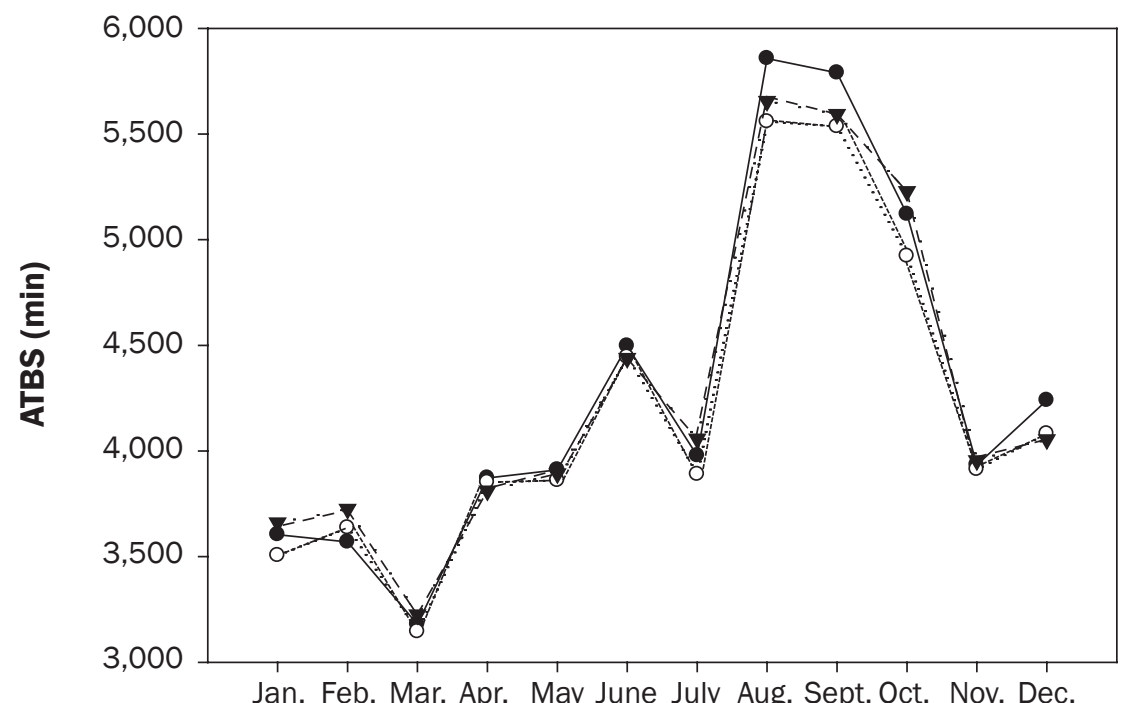

Month

\section{Legend}

$\longrightarrow$ NAEW $103-\cdots-$ NAEW $109 \quad-\boldsymbol{\nabla}$ - - NAEW 115

table 2), with an average of 387 . The sample size was reduced to approximately $50 \%$ to $80 \%$ of the $n$ used for the higher resolution data (lower table 2). The smaller number of values makes the estimates of MTBS and ATBS more sensitive to larger infrequent
TBS values, explaining the larger CVs of the coarser data.

It may be possible to develop an equation that will convert coarse- to high-resolution data for both parameters; however, this is beyond the scope of the present paper. Such a study could extend the utility of the NWS

\section{Table 3}

Long-term average time between storms (ATBS) for North Appalachian Experimental Watershed (NAEW) rain gauges for both resolutions (data collapsed across all years for each month; average numbers of samples for ATBS same as for minimum time between storms [MTBS] in table 2 for each resolution).

\begin{tabular}{|c|c|c|c|c|c|c|c|c|c|c|c|c|c|}
\hline $\begin{array}{l}\text { Rain } \\
\text { gauge } \\
\text { ID }\end{array}$ & $\begin{array}{l}\text { Depth } \\
\text { resolution } \\
(\mathrm{mm})\end{array}$ & Jan. & Feb. & Mar. & Apr. & May & June & July & Aug. & Sept. & Oct. & Nov. & Dec. \\
\hline 103 & 0.25 & 3,604 & 3,570 & 3,180 & 3,872 & 3,911 & 4,497 & 3,978 & 5,857 & 5,790 & 5,120 & 3,934 & 4,240 \\
\hline \multirow[t]{2}{*}{115} & 0.25 & 3,660 & 3,725 & 3,225 & 3,811 & 3,892 & 4,439 & 4,058 & 5,655 & 5,593 & 5,228 & 3,955 & 4,054 \\
\hline & Average & 3,590 & 3,644 & 3,183 & 3,845 & 3,888 & 4,460 & 3,975 & 5,690 & 5,639 & 5,090 & 3,934 & 4,125 \\
\hline 109 & 2.54 & 7306 & 7,219 & 5,714 & 6,547 & 5,341 & 6,037 & 5,357 & 7,873 & 8,866 & 8,945 & 7,018 & 7,777 \\
\hline \multirow[t]{4}{*}{115} & 2.54 & 9,847 & 9,445 & 6,850 & 7,345 & 5,841 & 6,078 & 5,655 & 7,775 & 9,260 & 9,826 & 10,202 & 9,094 \\
\hline & Average & 8,401 & 8,503 & 6,559 & 7,105 & 5,659 & 6,096 & 5,542 & 8,268 & 9,625 & 9,387 & 10,248 & 8,375 \\
\hline & $\mathrm{CV}$ & 16 & 14 & 11 & 7 & 5 & 1 & 3 & 9 & 10 & 5 & 32 & 8 \\
\hline & $\begin{array}{l}\text { Ratio Resol } \\
\quad(2.54 / 0.25)\end{array}$ & 2.3 & 2.3 & 2.1 & 1.8 & 1.5 & 1.4 & 1.4 & 1.5 & 1.7 & 1.8 & 2.6 & 2.0 \\
\hline
\end{tabular}

* CV $=$ coefficient of variation (\%). 
coarse data set for climate change and model-parameter studies. The data suggest that there may be a statistically significant relation between the two resolutions but that estimating both parameters from coarser resolution data may require a stochastic approach due to the variability. Also, while depth resolution was changed in the present paper, studies by Bonta and Rao (1988) showed that 3-minute and 60-minute NAEW data with the same depth resolution $(0.25 \mathrm{~mm}$ [0.01 in]) did not noticeably change MTBS values. This suggests that the depth resolution of precipitation data is more important than time resolution. With coarser (60 minute) time resolution data, the error would be no more than two hours, while increasing the depth resolution can extend dry times greatly.

Temporal and Among-Gauge Variations of Times-Between-Storms Parameters over the North Appalachian Experimental Watershed. Time trends of five-year NAEW MTBS (0.25 mm [0.01 in]) data showed large variability about the unity line prior to the early 1970s, followed by less variability (e.g., November shown in figure 8). The variability is due to two factors: (1) there were two to three large drought periods in Ohio, and (2) the starting year for each gauge record was offset by one year starting in 1939 (table 1). Rogers (2011) states there were drought periods in Ohio occurring in 1940, 1952 to 1954,1962 to $1965,1988,1991$ to 1992, 1999, and 2002 (gray rectangles). The drought in the 1950s was the worst since the droughts that occurred in the 1930s. In 1988, the drought was severe but lasted only four months. The two prolonged periods in the 1950s and 1960s cause the MTBS estimates to vary greatly, whereas the shorter periods do not influence variability as much. The variability of individual estimates for periods is also affected by the offset of the beginning year for each five-year series-each period will have a different weight of long dry periods used in exponential-method calculations. Most NAEW and NWS gauges in Ohio will be affected by these droughts. Figure 8 is an example of the trend of five-year periods when there is no statistically significant trend for November MTBS.

The corresponding November NAEW ATBS $(0.25 \mathrm{~mm}$ [0.01 in]) data showed much less variability about the unity line (figure 9). The deviations from unity during drought periods were larger than the overall ATBS value, but the variability is much

\section{Figure 8}

Trends of ratios of minimum time between storms (MTBS) versus midpoint of five-year periods to MTBS ( $0.25 \mathrm{~mm}$ resolution) from using all data collapsed across years for November for three North Appalachian Experimental Watershed (NAEW) rain gauges (vertical regions are periods of drought in Ohio except for vertical line at 1979).

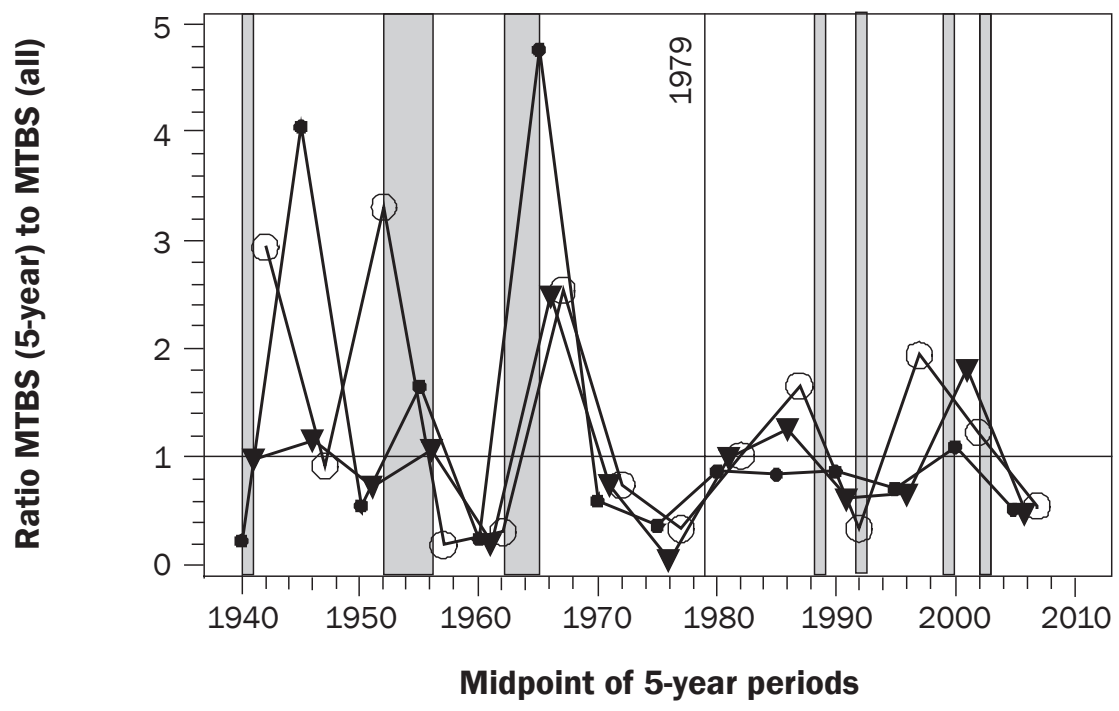

\section{Legend}

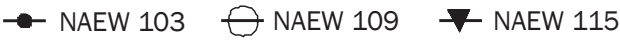

\section{Figure 9}

Trends of ratios of average time between storms (ATBS) versus midpoint of five-year periods to ATBS ( $0.25 \mathrm{~mm}$ resolution), from using all data collapsed across years for November for three North Appalachian Experimental Watershed (NAEW) rain gauges (vertical regions are periods of drought in Ohio except for vertical line at 1979).

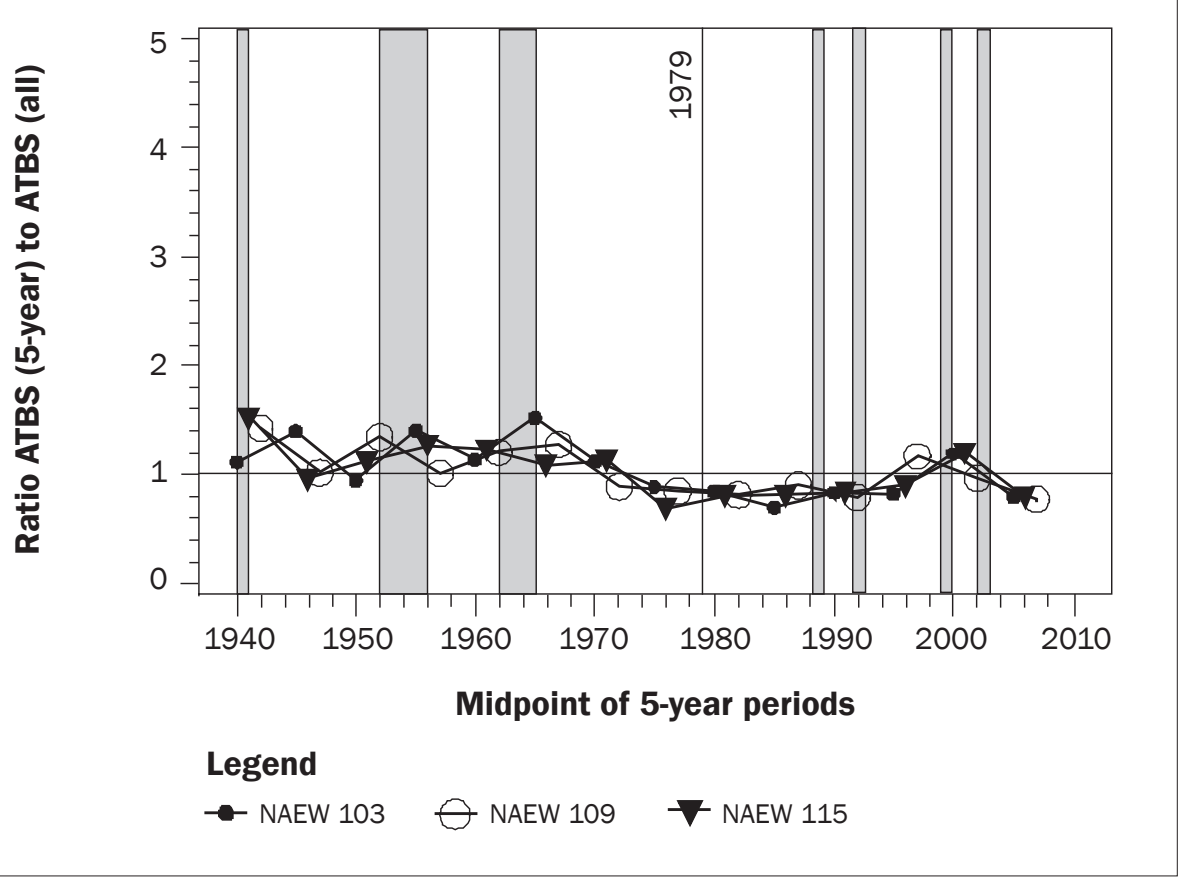


smaller than for MTBS (vertical scales in figure 8 and figure 9 are the same for comparison purposes). Figure 9 is an example of a statistically significant trend in fiveyear periods (all three gauges significant). Visually and statistically, the points show a shortening of ATBS with time. The average slope from computing a linear regression line for each of the three gauges in figure 9 is -27 minutes per five-year period (average $p$-value is 0.025). From 1940 to 2010, this is a 378-minute (6.3-hour) decrease in average TBS. The significant trends, however, will be influenced by the major droughts in the 1950s and 1960s. Figure 10a shows no significant trends for MTBS except for February and August for NAEW-115 (points joined by lines). However, figure 10b shows the three significant trends in ATBS for November in figure 9, as well as one in September for NAEW-103.

Trends in NAEW data after 1979 were not statistically significant for either MTBS ( $p$-values ranged from 0.467 to 0.872 ) or ATBS ( $p$-values ranged from 0.788 to 0.957 )

In both figure 8 and figure 9 , the longterm value appears to be representative of the group of five-year values, more so with MTBS. The MTBS values are more sensitive to periods of drought compared with the corresponding ATBS values. Based on these results, even using the clustered high-resolution NAEW data will yield highly variable MTBS results, while the corresponding ATBS results show much less variability. This suggests that much variability can be expected in MTBS results from using the broader Ohio NWS data in this study.

\section{Long-Term Times-Between-Storms} Parameters of National Weather Service Gauges. Table 4 shows the individual monthly MTBS parameters for NWS data collapsed across years with a $0.25 \mathrm{~mm}$ (0.01 in) depth resolution. The average MTBS of NWS gauges was always greater than the average NAEW MTBS for each month, ranging from 1.09 to 2.41 times, with an average of 1.58 times. Average MTBS ranged from 223 to 1,406 minutes, with an average of 527 minutes, compared with an average of 362 minutes for NAEW gauges. MTBS CVs for the NWS gauges ranged from $21 \%$ to $60 \%$. The magnitude and variability is likely due to spatial variability, expected spatial variability (e.g., as shown by NAEW data), time resolution of data, and instrument-related variability. The

Figure 10

Rank-correlation significance probabilities for each month for (a) minimum time between storms (MTBS) and (b) average time between storms (ATBS) using precipitation gauges with $0.25 \mathrm{~mm}$ depth resolution during entire record (North Appalachian Experimental Watershed [NAEW] gauge values connected with lines).

(a)

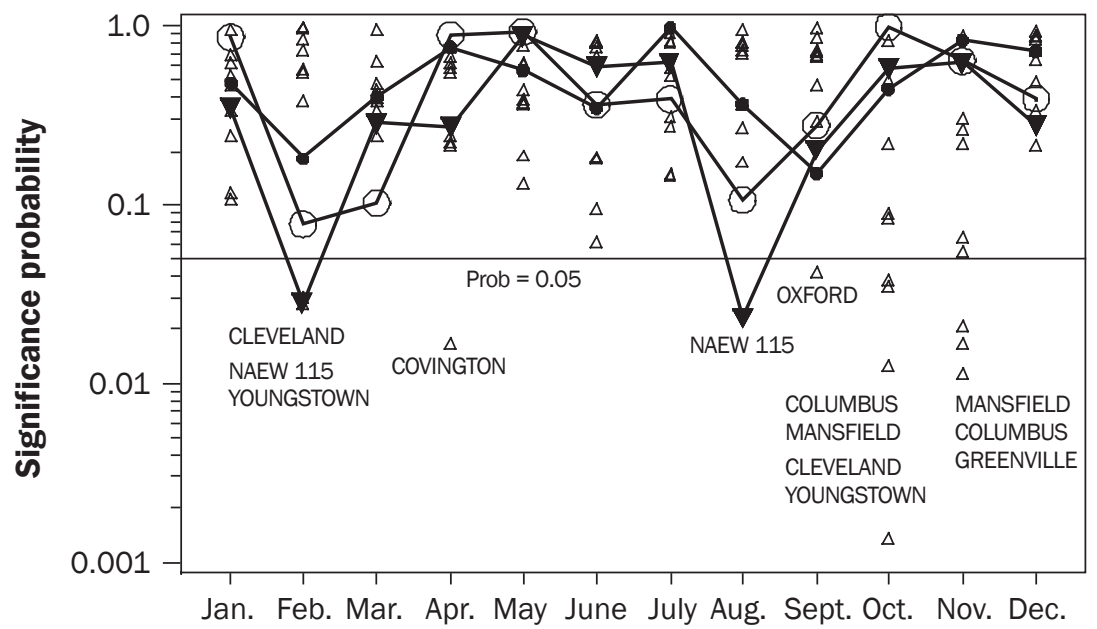

Month

(b)

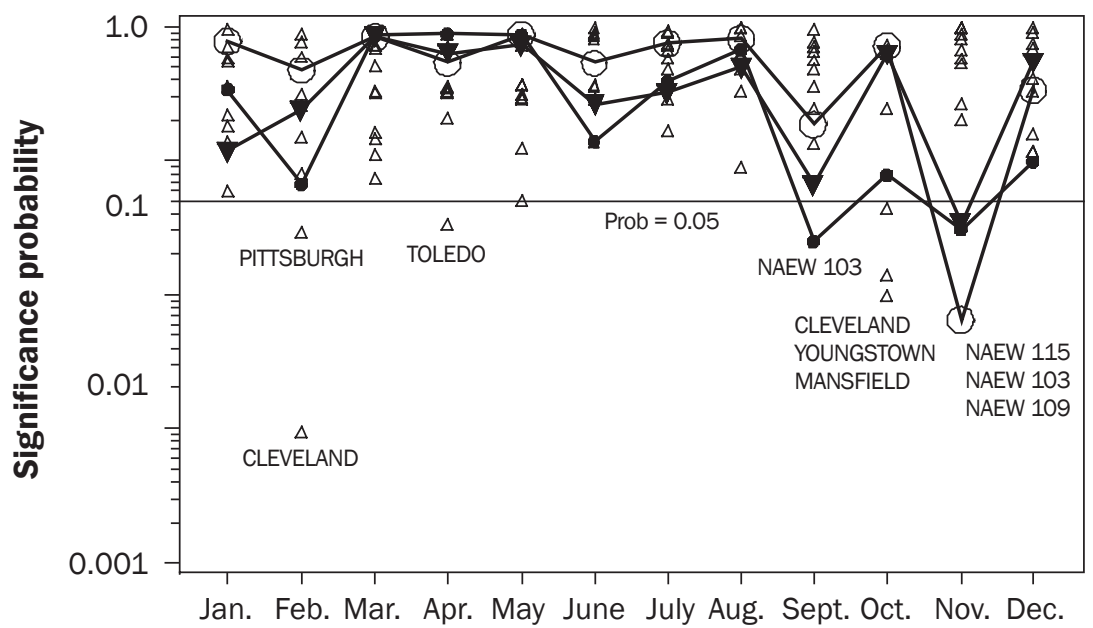

Month

\section{Legend}

$\rightarrow$ NAEW $103 \quad$ NAEW $109 \quad$ ₹ NAEW $115 \quad \triangle$ NOAA/NWS

latter could be due to unknown erroneous dry periods between storms shorter than the long uncoded periods found in the data.

Table 5 shows corresponding ATBS for the NWS gauges with a $0.25 \mathrm{~mm}(0.01$ in) resolution collapsed across years for the entire period of record. The average ATBS of NWS gauges was also always greater than the average NAEW ATBS for each month but not as much as for MTBS, ranging from 1.03 to 1.22 times (average of 1.11 times).
Average ATBS ranged from 2,385 minutes (1.7 days) to 8,031 minutes (5.6 days), with an average of 4,689 minutes (3.3 days), compared with an average of 4,255 minutes (3 days) for NAEW gauges. The ATBS CVs for the NWS gauges ranged from $13 \%$ to $33 \%$. Factors affecting variability are the same as for MTBS. However, it is apparent that ATBS variability is much less than for MTBS, as found for the NAEW gauges. 
Table 4

Long-term minimum time between storms (MTBS [minutes]) for National Weather Service (NWS) precipitation gauges in Ohio (0.25 mm resolution).

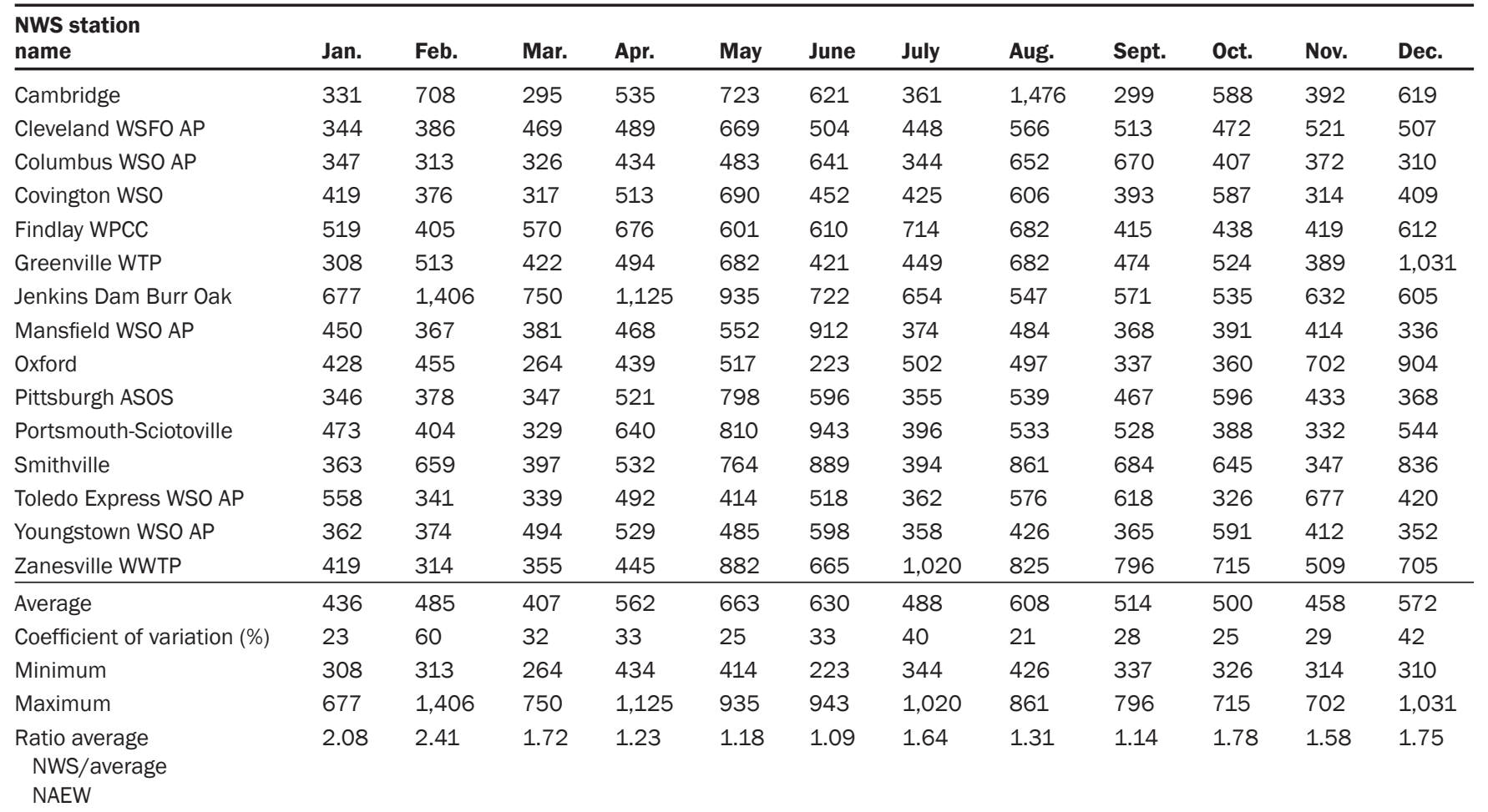

Table 5

Long-term average time between storms (ATBS [minutes]) for National Weather Service (NWS) precipitation gauges in Ohio (0.25 mm resolution).

\begin{tabular}{|c|c|c|c|c|c|c|c|c|c|c|c|c|}
\hline $\begin{array}{l}\text { NWS station } \\
\text { name }\end{array}$ & Jan. & Feb. & Mar. & Apr. & May & June & July & Aug. & Sept. & Oct. & Nov. & Dec. \\
\hline Cambridge & 4,052 & 5,202 & 3,519 & 4,657 & 5,054 & 5,139 & 4,748 & 8,031 & 5,432 & 6,009 & 4,716 & 5,413 \\
\hline Cleveland WSFO AP & 2,440 & 2,761 & 2,969 & 3,254 & 3,879 & 4,041 & 4,328 & 4,757 & 4,506 & 4,031 & 3,130 & 2,872 \\
\hline Covington WSO & 3,618 & 3,876 & 3,113 & 3,682 & 4,087 & 4,061 & 4,090 & 5,488 & 5,569 & 5,775 & 3,911 & 3,781 \\
\hline Findlay WPCC & 5,476 & 4,994 & 4,841 & 4,747 & 5,066 & 5,044 & 5,672 & 6,726 & 5,940 & 6,024 & 4,665 & 5,391 \\
\hline Mansfield WSO AP & 3,566 & 3,524 & 3,113 & 3,200 & 3,558 & 4,634 & 4,249 & 4,832 & 4,543 & 4,739 & 3,436 & 3,162 \\
\hline Oxford & 5,737 & 6,172 & 4,319 & 4,629 & 4,712 & 4,362 & 5,893 & 7,106 & 6,412 & 6,961 & 6,237 & 7,016 \\
\hline Pittsburgh ASOS & 2,512 & 2,872 & 2,677 & 3,466 & 4,027 & 3,768 & 3,772 & 4,752 & 4,570 & 4,653 & 3,313 & 2,898 \\
\hline Portsmouth-Sciotoville & 4,931 & 4,668 & 3,831 & 5,020 & 5,276 & 5,526 & 4,595 & 5,969 & 6,828 & 6,417 & 4,500 & 5,039 \\
\hline Smithville & 4,006 & 5,019 & 3,859 & 4,393 & 4,754 & 5,558 & 4,142 & 6,695 & 6,617 & 6,409 & 4,384 & 5,500 \\
\hline Coefficient of variation (\%) & 28 & 29 & 19 & 19 & 17 & 13 & 16 & 18 & 18 & 16 & 22 & 33 \\
\hline Minimum & 2,440 & 2,761 & 2,677 & 3,200 & 3,401 & 3,768 & 3,772 & 4,488 & 4,229 & 4,031 & 2,803 & 2,385 \\
\hline Maximum & 5,737 & 6,777 & 4,841 & 5,930 & 5,548 & 5,558 & 5,893 & 8,031 & 7,331 & 6,961 & 6,237 & 7,077 \\
\hline $\begin{array}{l}\text { Ratio average } \\
\text { NWS/average } \\
\text { NAEW }\end{array}$ & 1.14 & 1.22 & 1.15 & 1.08 & 1.13 & 1.05 & 1.18 & 1.05 & 1.03 & 1.09 & 1.10 & 1.09 \\
\hline
\end{tabular}


The individual MTBS and ATBS values using a coarser depth resolution of 2.54 $\mathrm{mm}$ (0.1 in) for NWS data were computed but not presented. All results were similar to those presented for the NAEW gaugesgenerally longer values compared with 0.25 $\mathrm{mm}$ (0.01 in) resolution data. However, the trends in these data over five-year periods are presented.

Temporal Variation of Time-BetweenStorm Parameters over Ohio. The graph of statistical significance levels ( $p$-values) from the rank-correlation procedure for 0.25 (0.01 in) $\mathrm{mm}$ resolution data (figure $10 \mathrm{a})$ shows that most $p$-values are greater than 0.05 , with the majority having values much greater than 0.1 . Thus, the trends of plots (similar to figure 8) for nearly all Ohio gauges with $0.25 \mathrm{~mm}$ resolution were not statistically significant over the period of record for each gauge. Monthly MTBS and ATBS values from 9 NWS and 3 NAEW gauges (12 gauges) yielded 144 values for each. Of this total, only $13(9 \%)$ were significant. Nine percent is slightly larger than the $5 \%$ probability level and suggests that if there is an overall trend due to climate change over Ohio, it is of borderline significance. Figure $10 \mathrm{a}$ shows that months with the greatest numbers of significant trends were mostly October, February, and November, and less so for April, August, and September. Table 6 shows the 13 gauges and the trends of fiveyear periods -6 months lengthening and 10 months shorting in duration. The significant gauges were not located in a common area of Ohio across months. However, October had three gauges in the northeastern quadrant of Ohio, all of which were shortening, but more data in this area is needed to validate this finding. No region of Ohio was clearly changing significantly.

The lines in the plots (figure 10a) show the trends of significance probabilities for NAEW gauges. Only two months had significant trends for gauge NAEW-115, February and August. The other NAEW gauges did not show significance for all months. Significance was found for 2 of 36 values $(\sim 6 \%)$, the same order as the 0.05 $p$-value, suggesting no significant, or borderline significant, trend due to climate change at the NAEW.

Figure 10b shows a similar probability plot for ATBS for results. As before, most results did not show a statistically significant trend (only 9 out of 144 , or $6 \%$ were significant),

\section{Table 6}

Rank-correlation significance probabilities $\leq 0.05$ for each month for minimum time between storms (MTBS) using precipitation gauges with $0.25 \mathrm{~mm}$ and $2.54 \mathrm{~mm}$ depth resolutions during entire record.

\begin{tabular}{|c|c|c|c|c|c|}
\hline \multirow[b]{2}{*}{ Month } & \multirow[b]{2}{*}{$\begin{array}{l}\text { Station } \\
\text { name }\end{array}$} & \multicolumn{2}{|c|}{ Resolution } & \multirow[b]{2}{*}{$\begin{array}{l}\text { Significance } \\
\text { probability }\end{array}$} & \multirow[b]{2}{*}{$\begin{array}{l}\text { Shorter (s) } \\
\text { or longer (L)* }\end{array}$} \\
\hline & & $\begin{array}{l}\text { Time } \\
\text { (min) }\end{array}$ & $\begin{array}{l}\text { Depth } \\
(\mathrm{mm})\end{array}$ & & \\
\hline Jan. & Toledo Express WSO AP & 60 & 2.54 & 0.004 & s \\
\hline Feb. & Cleveland WSFO AP & 60 & 0.25 & 0.028 & L \\
\hline Feb. & NAEW-115 & 1 & 0.25 & 0.029 & L \\
\hline Feb. & Youngstown WSO AP & 60 & 0.25 & 0.031 & L \\
\hline Apr. & Covington WSO & 60 & 0.25 & 0.017 & s \\
\hline July & Cleveland WSFO AP & 60 & 2.54 & 0.006 & $\mathrm{~L}$ \\
\hline July & Mansfield WSO AP & 60 & 2.54 & 0.035 & s \\
\hline Aug. & NAEW-115 & 1 & 0.25 & 0.023 & $\mathrm{~L}$ \\
\hline Sept. & Oxford & 60 & 0.25 & 0.043 & s \\
\hline Oct. & Youngstown WSO AP & 60 & 0.25 & 0.001 & s \\
\hline Oct. & Cleveland WSFO AP & 60 & 0.25 & 0.013 & s \\
\hline Oct. & Mansfield WSO AP & 60 & 0.25 & 0.035 & s \\
\hline Oct. & Columbus WSO AP & 60 & 0.25 & 0.039 & s \\
\hline Nov. & Greenville WTP & 60 & 0.25 & 0.011 & L \\
\hline Nov. & Columbus WSO AP & 60 & 0.25 & 0.017 & s \\
\hline Nov. & Mansfield WSO AP & 60 & 0.25 & 0.021 & s \\
\hline
\end{tabular}

*This column represents the trend of significant change, whether shorter or longer duration.

again suggesting a borderline change, if any. For October, three of the same gauges showed significance as for MTBS.All NAEW gauges showed significance for November as mentioned earlier. Table 7 shows information for individual gauges in figure $10 \mathrm{~b}$ for statistically significant gauges. Some gauges show shortening and some show lengthening (table 7), with some clustering in the northeastern part of Ohio (shortening in October, the same as found for MTBS).

For both MTBS and ATBS, the graphs of ratios versus midpoints of five-year periods were similar to those for the NAEW. There is a hint that there is some change occurring during the months of October and November, and some indication that a change may be occurring in northeastern Ohio. However, more data are necessary to make firm conclusions about the effects of climate change.

Since 1979, the number of significance probabilities for combined regional NWS and NAEW MTBS and ATBS using the $0.25 \mathrm{~mm}(0.01 \mathrm{in})$ resolution were $5(3 \%)$ and $11(8 \%)$, respectively. Of these totals, only one NAEW gauge was significant for MTBS, and two were significant for ATBS. Similarly, for a $2.54 \mathrm{~mm}(0.1 \mathrm{in})$ resolution, three regional gauges $(2 \%)$ were significant for MTBS, and five for ATBS (3\%). Of these, only one NAEW gauge was significant for MTBS and zero for ATBS. In all cases, there was no apparent strong spatial or monthly grouping of significant trends to indicate a change due to climate.

Effects of Depth Resolution of Data on Temporal Variability of Times-BetweenStorms Parameters. Figure 11a shows that when depth resolution changes from 0.25 $\mathrm{mm}$ to $2.54 \mathrm{~mm}$ (0.01 to $0.1 \mathrm{in}$ ) there are only three significant values. Two of the gauges involved are Mansfield and Cleveland, the same gauges in the northeastern part of Ohio found significant in the $0.25 \mathrm{~mm}$ resolution analyses. However, the results for these two gauges were in July and not October as with the $0.25 \mathrm{~mm}$ resolution trends. Table 6 shows that the trends for Toledo and Mansfield were a shortening of ATBS and for Cleveland was a lengthening. However, the percentage of significant values $(2 \%)$ is less than expected at the $p$-value of 0.05 , suggesting no effects of climate detected with the coarser resolution data. No NAEW gauges were significant under the coarser resolution.

Figure $11 \mathrm{~b}$ shows more significant effects of climate change for ATBS than for MTBS for coarser resolution data-12 out of 144 $(8 \%)$ were significant. This percentage is again of the order of the $p$-value, and the significant gauges were scattered across Ohio. 
Table 7

Significance probabilities $\leq \mathbf{0 . 0 5}$ for each month for average time between storms (ATBS) using precipitation gauges with $0.25 \mathrm{~mm}$ and $2.54 \mathrm{~mm}$ depth resolutions during entire record.

\begin{tabular}{|c|c|c|c|c|c|}
\hline \multirow[b]{2}{*}{ Month } & \multirow[b]{2}{*}{$\begin{array}{l}\text { Station } \\
\text { name }\end{array}$} & \multicolumn{2}{|c|}{ Resolution } & \multirow[b]{2}{*}{$\begin{array}{l}\text { Significance } \\
\text { probability }\end{array}$} & \multirow[b]{2}{*}{$\begin{array}{l}\text { Shorter }(\mathbf{s}) \\
\text { or longer }(\mathbf{L}) *\end{array}$} \\
\hline & & $\begin{array}{l}\text { Time } \\
(\min )\end{array}$ & $\begin{array}{l}\text { Depth } \\
(\mathrm{mm})\end{array}$ & & \\
\hline Jan. & Toledo Express WSO AP & 60 & 2.54 & 0.007 & s \\
\hline Jan. & NAEW-103 & 1 & 2.54 & 0.041 & $\mathrm{~L}$ \\
\hline Feb. & Cleveland WSFO AP & 60 & 0.25 & 0.001 & $\mathrm{~L}$ \\
\hline Feb. & Pittsburgh ASOS & 60 & 0.25 & 0.029 & $\mathrm{~L}$ \\
\hline Feb. & NAEW-115 & 1 & 2.54 & 0.004 & $\mathrm{~L}$ \\
\hline Feb. & NAEW-103 & 1 & 2.54 & 0.005 & $\mathrm{~L}$ \\
\hline Feb. & Youngstown WSO AP & 60 & 2.54 & 0.024 & $\mathrm{~L}$ \\
\hline Mar. & NAEW-115 & 1 & 2.54 & 0.020 & $\mathrm{~L}$ \\
\hline Mar. & Cleveland WSFO AP & 60 & 2.54 & 0.024 & $\mathrm{~L}$ \\
\hline Apr. & Toledo Express WSO AP & 60 & 0.25 & 0.033 & $\mathrm{~L}$ \\
\hline Apr. & Toledo Express WSO AP & 60 & 2.54 & 0.011 & $\mathrm{~L}$ \\
\hline May & Covington WSO & 60 & 2.54 & 0.007 & $\mathrm{~s}$ \\
\hline June & NAEW-103 & 1 & 2.54 & 0.014 & $\mathrm{~L}$ \\
\hline June & NAEW-109 & 1 & 2.54 & 0.034 & L \\
\hline Sept. & NAEW-103 & 1 & 0.25 & 0.025 & $\mathrm{~s}$ \\
\hline Sept. & Greenville WTP & 60 & 2.54 & 0.043 & $\mathrm{~s}$ \\
\hline Oct. & Mansfield WSO AP & 60 & 0.25 & 0.010 & $\mathrm{~s}$ \\
\hline Oct. & Youngstown WSO AP & 60 & 0.25 & 0.014 & $\mathrm{~s}$ \\
\hline Oct. & Cleveland WSFO AP & 60 & 0.25 & 0.045 & $\mathrm{~s}$ \\
\hline Oct. & Cleveland WSFO AP & 60 & 2.54 & 0.020 & $\mathrm{~s}$ \\
\hline Nov. & NAEW-109 & 1 & 0.25 & 0.007 & $\mathrm{~s}$ \\
\hline Nov. & NAEW-103 & 1 & 0.25 & 0.030 & $\mathrm{~s}$ \\
\hline Nov. & NAEW-115 & 1 & 0.25 & 0.034 & $\mathrm{~s}$ \\
\hline
\end{tabular}

*This column represents the trend of significant change, whether shorter or longer duration.

However, there were more significant values in the winter and spring, compared with the fall months in figure 10b. In three months, 1 or 2 NAEW gauges were significant. Table 7 shows that there was lengthening of ATBS in 9 gauges $(70 \%)$ and shortening for 4 gauges (30\%).

Effects on Trend Detection Due to Mixed Resolution Data and Resolution Change. Table 8 shows gauges with trend $p$-values less than or equal to 0.05 for the 6 gauges having mixed resolutions original data series (table 1). In each case, the trend is for longer MTBS values. There were 11 of 72 (15\%) of $p$-values that were significant. These results most likely have many false positive values due to the coarsening of resolution as shown in figure 5 for ATBS. When the entire data record was subjected to the coarser resolution to make the record have a uniform resolution of $2.54 \mathrm{~mm}$ (0.1 in), there were only 5 of 72 $(7 \%)$ that were significant, half of the number for mixed resolution results. The gauges that were significant with the coarser resolution were not the same as those for a uniform record subjected to a $2.54 \mathrm{~mm}$ resolution. Analyzing a mixed resolution record without adjusting the earlier records will give many false positives due to the changing resolution (figure 5), and making it uniform will reduce in half the number of significant values.

Approximately the same percentage of significant values were found for ATBS results for mixed resolution data (table 9; $9 \div 72=$ $13 \%)$ as for MTBS (15\%). However, when the records were made coarser to form a uniform resolution through time, the percentage increased to $15 \%(11 \div 72)$. These inconsistent results suggest that, unless some other adjustment is made to the data record, that the mixed resolution data cannot be used to detect climate changes of dry periods.

Suggestions for Further Research. This study suggests several areas for further research. Some examples are the following:

- Perform the regional analysis using data that have undergone preparation as performed by Bonta (2001). Briefly, this involves eliminating dry periods identified in a recording gauge record that were not dry according to an adjacent storage-gauge record.

- Explore relations between TBS parameters developed from 24-hour and breakpoint data to potentially expand the data base.

- Explore relations between TBS parameters developed from 0.25 and $2.54 \mathrm{~mm}(0.01$ and $0.1 \mathrm{in})$ data to potentially expand the data base by converting coarse-resolution data to high-resolution data.

- Explore a mixed exponential method or other methodology to improve quantification of frequent and infrequent dry times. This might include incorporating large-scale atmospheric forcings.

- Using NAEW data, investigate how changes in air temperature are affecting evapotranspiration, ground-water recharge, and other components of the hydrological cycle, particularly for the TBS.

\section{Summary and Conclusions}

Quantifying magnitudes of rainless TBS, or storm occurrence, over small spatial and short temporal scales is required for modeling precipitation inputs to watershed models for conservation studies, particularly small watersheds. This is because identification of storms in a precipitation record depends on a MTBS and ATBS that vary monthly. The two parameters are determined objectively from the exponential method for identifying storms. If climate changes are impacting TBS, then the trends and specific effects of climate change also require identification and quantification.

A problem in analyzing precipitation data arises because data characteristics vary depending on the source of the records. Precipitation data having one-minute temporal and $0.25 \mathrm{~mm}(0.1 \mathrm{in})$ depth resolutions (termed "high resolution") from the UDSA ARS NAEW at Coshocton, Ohio, were used to determine the impacts of "coarsening" the depth resolution of the data to 2.54 $\mathrm{mm}$ (0.1 in), characteristics often found in NWS records. The magnitudes and trends of changes in MTBS and ATBS are determined for three NAEW rain gauges that are triangularly located about $1.5 \mathrm{~km}$ (0.9 mi) from each other (figure 1).

These results provide insight to variability of magnitudes and statistically significant trends over a small 425 ha $(1,050 \mathrm{ac})$ area. The procedure was repeated for NWS data that have hourly time resolution and 0.25- 


\section{Figure 11}

Rank-correlation significance probabilities for each month for (a) minimum time between storms (MTBS) and (b) average time between storms (ATBS) using precipitation gauges with $2.54 \mathrm{~mm}$ depth resolution during entire record (North Appalachian Experimental Watershed [NAEW] gauge values connected with lines).

(a)

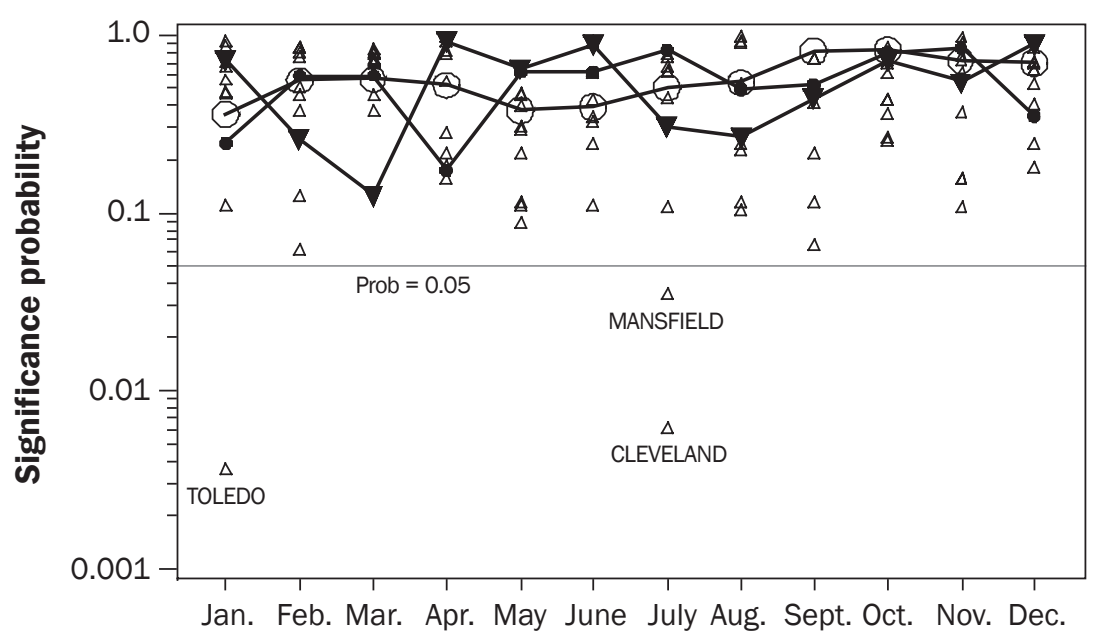

Month

(b)

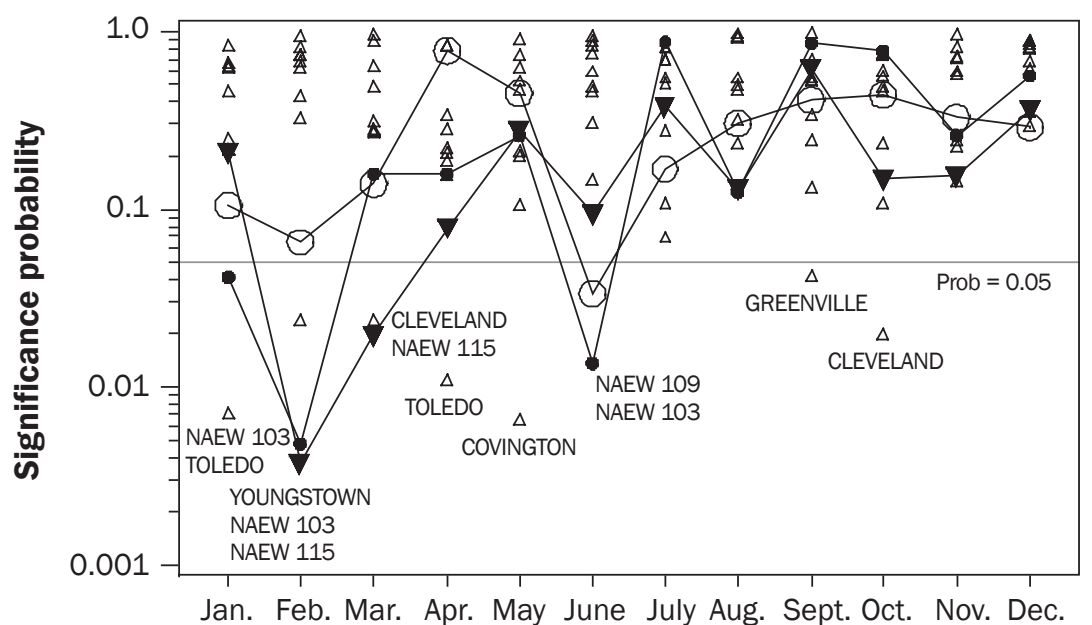

Month

\section{Legend}

- NAEW 103

@ NAEW 109

- NAEW 115

$\triangle$ NOAA/NWS

$\mathrm{mm}, 2.54 \mathrm{~mm}(0.01,0.1 \mathrm{in})$ and mixed depth resolution data over Ohio. The coarser and mixed NWS data are available widely over the United States. The broad objectives were to determine the utility of the coarser records using NAEW and NWS data that complement each other. The term "long-term" refers to parameter estimates collapsed across years for each month, and the term "temporal variability" or "trend" refers to the trend of 5-year monthly TBS parameter estimates. Approximately 5,800 pairs of MTBS and ATBS values were computed from 18 rain gauges in the Ohio region, with record lengths of approximately 62 years through most of 2010, and by using different data configurations.

Conclusions regarding magnitudes and statistically significant trends from the cluster of three NAEW gauges include the following: - While long-term values of the two TBS parameters are consistent across the
NAEW, long-term variability of MTBS is greater than for ATBS.

- Long-term maximum and minimum MTBS and ATBS values do not occur in the same month.

- More variability can be expected for trends in MTBS than for ATBS.

- It is possible for at least one gauge to show a significant trend for either parameter in a month, suggesting that a single gauge in an area may not suffice for detecting climate changes and that more data are needed.

- Monthly MTBS is greatly different than a six-hour fixed value often used to identify storms.

- For ATBS, all three gauges consistently identified November as a month of shortening ATBS (-27 min per 5-year period). Between 1940 and 2010, this is a reduction in ATBS of 378 minutes (6.3 hour).

- There was no significant trend in MTBS or ATBS from 1979 through 2010.

- When depth resolution is coarsened to $2.54 \mathrm{~mm}$ (0.1 in), long-term MTBS and ATBS are consistently lengthened, there is more variability in estimates, and the numbers of durations used in calculations is greatly reduced.

- Compared with another study, time resolution differences in the data are not as important as depth resolution differences.

- A coarser resolution yields no significant trends in MTBS but can shift significance from the fall to winter for ATBS. It can give more definitive results for trends in MTBS, but inconsistent results for closely spaced gauges for ATBS.

Conclusions regarding magnitudes and statistically significant trends from the more regional Ohio gauges include the following:

- More trends were found in the 0.25 $\mathrm{mm}$ (0.01 in) resolution data in the fall for MTBS. There was some indication that these trends occurred more often in the northeastern part of the state than elsewhere.

- For ATBS, more significant shortening trends were found in the northeastern part of the state and as far south as the NAEW.This suggests that storm durations may be lengthening.

- Coarser depth-resolution data reduced the number of significant trends for MTBS.

- Coarser depth-resolution data shifted the number of significant trends from the fall (shorter durations) to winter (longer 


\section{Table 8}

Rank-correlation significance probabilities $\leq 0.05$ for each month for minimum time between storms (MTBS) using precipitation gauges with mixed-depth resolution gauges during entire record.

\begin{tabular}{|c|c|c|c|c|c|}
\hline \multirow[b]{2}{*}{ Month } & \multirow[b]{2}{*}{$\begin{array}{l}\text { Station } \\
\text { name }\end{array}$} & \multicolumn{2}{|c|}{ Resolution } & \multirow[b]{2}{*}{$\begin{array}{l}\text { Significance } \\
\text { probability }\end{array}$} & \multirow[b]{2}{*}{$\begin{array}{l}\text { Shorter (s) } \\
\text { or longer (L)* }\end{array}$} \\
\hline & & $\begin{array}{l}\text { Time } \\
\text { (min) }\end{array}$ & $\begin{array}{l}\text { Depth } \\
(\mathrm{mm}) \dagger\end{array}$ & & \\
\hline Jan. & Jenkins Dam Burr Oak & 60 & Mixed & 0.005 & L \\
\hline Jan. & Portsmouth-Sciotoville & 60 & Mixed & 0.032 & $\mathrm{~L}$ \\
\hline Jan. & Findlay WPCC & 60 & Mixed & 0.036 & $\mathrm{~L}$ \\
\hline Feb. & Zanesville WWTP & 60 & Mixed & 0.008 & $\mathrm{~L}$ \\
\hline Feb. & Smithville & 60 & Mixed & 0.020 & $\mathrm{~L}$ \\
\hline Feb. & Cambridge & 60 & Mixed & 0.021 & $\mathrm{~L}$ \\
\hline Feb. & Cambridge & 60 & 2.54 & 0.048 & $\mathrm{~L}$ \\
\hline Mar. & Smithville & 60 & Mixed & 0.008 & $\mathrm{~L}$ \\
\hline Mar. & Jenkins Dam Burr Oak & 60 & Mixed & 0.010 & $\mathrm{~L}$ \\
\hline Mar. & Zanesville WWTP & 60 & 2.54 & 0.015 & $\mathrm{~L}$ \\
\hline June & Cambridge & 60 & Mixed & 0.006 & $\mathrm{~L}$ \\
\hline June & Jenkins Dam Burr Oak & 60 & Mixed & 0.047 & $\mathrm{~L}$ \\
\hline June & Cambridge & 60 & 2.54 & 0.006 & $\mathrm{~L}$ \\
\hline June & Zanesville WWTP & 60 & 2.54 & 0.033 & $\mathrm{~L}$ \\
\hline July & Smithville & 60 & Mixed & 0.017 & $\mathrm{~L}$ \\
\hline Aug. & Smithville & 60 & 2.54 & 0.011 & $\mathrm{~L}$ \\
\hline
\end{tabular}

* This column represents the trend of significant change, whether shorter or longer duration.

† Mixed means that a nonuniform depth resolution in the original record was used. 2.54 means the data were made uniform by forcing all data to have coarser resolution.

\section{Table 9}

Rank-correlation significance $\leq \mathbf{0 . 0 5}$ for each month for average time between storms (ATBS) using precipitation gauges with mixed-depth resolution gauges during entire record.

\begin{tabular}{|c|c|c|c|c|c|}
\hline \multirow[b]{2}{*}{ Month } & \multirow[b]{2}{*}{$\begin{array}{l}\text { Station } \\
\text { name }\end{array}$} & \multicolumn{2}{|c|}{ Resolution } & \multirow[b]{2}{*}{$\begin{array}{l}\text { Significance } \\
\text { probability }\end{array}$} & \multirow[b]{2}{*}{$\begin{array}{l}\text { Shorter (s) } \\
\text { or longer (L)* }\end{array}$} \\
\hline & & $\begin{array}{l}\text { Time } \\
(\min )\end{array}$ & $\begin{array}{l}\text { Depth } \\
(\mathrm{mm})\end{array}$ & & \\
\hline Jan. & Jenkins Dam Burr Oak & 60 & 0.25 & 0.008 & $\mathrm{~L}$ \\
\hline Feb. & Smithville & 60 & 0.25 & 0.015 & $\mathrm{~L}$ \\
\hline Feb. & Cambridge & 60 & 0.25 & 0.043 & $\mathrm{~L}$ \\
\hline Mar. & Jenkins Dam Burr Oak & 60 & 0.25 & 0.010 & $\mathrm{~L}$ \\
\hline Mar. & Smithville & 60 & 0.25 & 0.045 & $\mathrm{~L}$ \\
\hline Mar. & Cambridge & 60 & 2.54 & 0.029 & $\mathrm{~s}$ \\
\hline Apr. & Findlay WPCC & 60 & 0.25 & 0.009 & $\mathrm{~L}$ \\
\hline June & Jenkins Dam Burr Oak & 60 & 0.25 & 0.013 & $\mathrm{~L}$ \\
\hline July & Jenkins Dam Burr Oak & 60 & 0.25 & 0.015 & $\mathrm{~L}$ \\
\hline Sept. & Portsmouth-Sciotoville & 60 & 2.54 & $<.001$ & $\mathrm{~s}$ \\
\hline Oct. & Zanesville WWTP & 60 & 2.54 & 0.002 & $\mathrm{~s}$ \\
\hline Oct. & Portsmouth-Sciotoville & 60 & 2.54 & 0.004 & $\mathrm{~s}$ \\
\hline Oct. & Jenkins Dam Burr Oak & 60 & 2.54 & 0.006 & $\mathrm{~s}$ \\
\hline Oct. & Cambridge & 60 & 2.54 & 0.010 & $\mathrm{~s}$ \\
\hline Oct. & Smithville & 60 & 2.54 & 0.045 & $\mathrm{~s}$ \\
\hline Nov. & Cambridge & 60 & 2.54 & 0.011 & $\mathrm{~s}$ \\
\hline Dec. & Smithville & 60 & 0.25 & 0.026 & $\mathrm{~L}$ \\
\hline Dec. & Zanesville WWTP & 60 & 2.54 & 0.001 & $\mathrm{~s}$ \\
\hline Dec. & Jenkins Dam Burr Oak & 60 & 2.54 & 0.002 & $\mathrm{~s}$ \\
\hline Dec. & Cambridge & 60 & 2.54 & 0.035 & $\mathrm{~s}$ \\
\hline
\end{tabular}

* This column represents the trend of significant change, whether shorter or longer duration. durations) months for ATBS and may be misleading regarding climate change.

- Analyzing a mixed-resolution record without adjusting the earlier records will give many false positives due to the changing resolution.

General conclusions include the following:

- Small spatial scale precipitation data show consistent MTBS and ATBS long-term values for each month with high-resolution data. Larger variations are likely due to data characteristics and differing measurement technologies.

- Trends for small spatial scale, high-resolution data are generally consistent, particularly for the NAEW.

- A coarser data resolution can give generally consistent trend indications for MTBS but not for ATBS.

- The exponential method results in more variability for estimates of MTBS than ATBS.

- There is a weak indication that the fall months may be affected by significant shortening of ATBS at the NAEW and in NE Ohio, but more data are needed. This suggests that storm durations may be lengthening.

- Significant climate change effects in Ohio may be influenced by droughts in the 1950s and 1960s.

- Coarse-resolution data may not be adequate to characterize and investigate TBS changes due to climate change unless more data manipulation is applied, such as identifying and excluding dry times when precipitation may have occurred. The results suggest that a more thorough treatment of the data is required prior to analysis. It also suggests that fewer data will be available because of the need for concurrent storage and recording rain-gauge data required for the more thorough data preparation.

- This paper gives guidance for a procedure to use NWS dry-period data to detect climate change. Unless an adjustment is made to the data record, mixed-resolution data cannot be used to detect climate changes of dry periods using the exponential method.

- Spatially collapsing data over an area may be one method to reduce variability, but the issue of statistical independence of data may require bootstrapping statistics or some other method of spatial averaging to increase homogeneity of the estimates. 
- More high-quality data are needed to arrive at firm conclusions regarding climate change effects on TBS in Ohio.

- The results provide guidance for exploring other NAEW data, such as precipitation and changes in evapotranspiration and ground-water recharge during dry periods.

- The results from the analysis of precipitation data suggest that researchers monitoring precipitation and using these data in investigations should consider consistency of depth and time resolutions of precipitation data in their plans.

\section{Acknowledgements}

The author is grateful to Phyllis Dieter, former USDA Agricultural Research Service biological lab technician, for aiding in preparation of figures.

\section{References}

Bonta, J.V. 2001. Characterizing and estimating spatial and temporal variability of times between storms. Transactions of the American Society of Agricultural Engineers 44(6):1593-1601.

Bonta, J.V. 2003. Estimation of parameters characterizing frequency distributions of times between storms. Transactions of the American Society of Agricultural Engineers 46(2):331-343.

Bonta, J.V. 2004. Stochastic simulation of storm occurrence, depth, duration, and within-storm intensities. Transactions of the American Society of Agricultural Engineers 47(5):1573-1584.

Bonta, J.V., and D. Barker. 2010. Effects of climate change on grass/legume growing season. North Appalachian Experimental Watershed Fact Sheet.

Bonta, J.V., and A. Nayak. 2008. Characterizing times between storms in mountainous areas. Transactions of the American Society of Agricultural and Biological Engineers 51(6):1-16.

Bonta, J.V., and A.R. Rao. 1988. Factors affecting the identification of independent storm events. Journal of Hydrology 98:275 293.

Delgado, J.A., P.M.Groffman, M.A. Nearing, T. Goddard, D. Reicosky, R. Lal, N.R. Kitchen, C.W. Rice, D. Towery, and P. Salon. 2011. Conservation practices to mitigate and adapt to climate change. Journal of Soil and Water Conservation 66(4):118A-129A, doi:10.2489/ jswc.66.4.118A.

Groisman, P.Y., and R.W. Knight. 2008. Prolonged dry episodes over the conterminous United States: New tendencies emerging during the last 40 years. Journal of Climate 21(9):1850-1862.

Groisman, P.Y., R.W. Knight, D.R. Easterling, T.R. Karl, C.G. Hegerl, and V.N. Razuvaev. 2005. Trends in intense precipitation in the climate record. Journal of Climate 18(9):1326-1350.
Groisman, P.Y., R.W. Knight, and T.R. Karl. 2001. Heavy precipitation and high streamflow in the contiguous United States: Trends in the twentieth century. Bulletin of the American Meteorological Society 82(2):219-246.

Harmel, R.D., J.V. Bonta, and C.W. Richardson. 2007. The original USDA-ARS experimental watersheds in Texas and Ohio: Contributions from the past and visions for the future. Transactions of the American Society of Agricultural and Biological Engineers 50(5):1669-1675

Huff, F.A. 1967. Time distribution of rainfall in heavy storms. Water Resources Research 3(4):1007-1019.

McGuinness, J.L. 1966. A comparison of lysimeter catch and rain gage catch. ARS-41-124.

National Weather Service. 2011. Monthly Station Normals of Temperature, Precipitation, and Heating and Cooling Degree Days, 1971-2000, Climatography of The United States No. 81. Silver Spring, MD: National Weather Service.

Nearing, M.A., F.F. Pruski, and M.R. O'Neal. 2004 Expected climate change impacts on soil erosion rates: A review. Journal of Soil and Water Conservation $59(1): 43-50$.

Owens, L.B., J.V. Bonta, and M.J. Shipitalo. 2010. USDAARS North Appalachian Experimental Watershed: 70-year hydrologic, soil erosion, and water quality data base. Soil Science Society of America Journal 74:619-623.

Pope, V., M.L. Gallani, P.R. Rowntree and R.A. Stratton, 2000. The impact of new physical parameterizations in the Hadley Centre climate model: HadAM3. Climate Dynamics 16:123-146.

PCMDI (Program for Climate Model Diagnosis and Intercomparison). Bias Corrected and Downscaled WCRP CMIP3 Climate Projections. http://gdo-dcp. ucllnl.org/downscaled_cmip3_projections/.

Pruski, F.F., and M.A. Nearing. 2002. Runoff and soil loss responses to changes in precipitation: A computer simulation study. Journal of Soil and Water Conservation 57(1):7-16.

Restrepo, P.J., and P.S. Eagleson. 1982. Identification of independent rainstorms. Journal of Hydrology 55:303-319.

Richardson, C.W., D.A. Bucks, and E.J. Sadler. 2008. The Conservation Effects Assessment Project benchmark watersheds: Synthesis of preliminary findings. Journal of Soil and Water Conservation 63(6): 590-604, doi:10.2489/jswc.63.6.590.

Rogers, J.C. 2011. Climate of Ohio. In Office of the State Climatologist for Ohio. Asheville, NC: National Climatic Data Center, Climate Services Branch. http:// www.geography.osu.edu/faculty/rogers/OOC.pdf.

Santhanam M.S., and H. Kantz. 2008. Return interval distribution of extreme events and long term memory. Physical Review E 78, 051113.

Trenberth, K.E., P.D. Jones, P. Ambenje, R. Bojariu, D. Easterling, A. Klein Tank, D. Parker, F. Rahimzadeh, J.A. Renwick, M. Rusticucci, B. Soden and P. Zhai.
2007:Observations: Surface and Atmospheric Climate Change. In Climate Change 2007: The Physical Science Basis. Contribution of Working Group I to the Fourth Assessment Report of the Intergovernmental Panel on Climate Change, eds. Solomon, S., D. Qin, M. Manning, Z. Chen, M. Marquis, K.B. Averyt, M. Tignor and H.L. Miller. Cambridge, United Kingdom and New York: Cambridge University Press. 